\title{
Modified foundation modelling of dowel embedment in glulam connections
}

\author{
V. Karagiannis ${ }^{\mathrm{a}}$, C. Málaga-Chuquitaype ${ }^{\mathrm{a} 1}$ and A.Y. Elghazouli ${ }^{\mathrm{a}}$ \\ ${ }^{a}$ Department of Civil and Environmental Engineering, Imperial College London, UK
} $(5$

\section{Abstract}

This paper examines the embedment behaviour of single-dowel connections in Scandinavian Spruce Glulam by means of experimental and numerical investigations. First, the experimental results of a series of single-dowel tests on samples of different geometry and grain directions are presented. The evolution of local strain concentrations around the fastener at increasing levels of bearing deformation, is reported in detail by means of non-contact field strain measurements and its implications are discussed. Detailed finite element simulations are also carried out and subsequently employed to highlight the main features of the response of doweled connections in glulam. A foundation model, initially developed for Douglas-fir (Pseudotsuga menziesii) timber, is upgraded and adapted for Scandinavian Spruce Glulam (Picea abies) elements subjected to loads acting perpendicular and parallel to the grain direction. The proposed model is based on the definition of equivalent material parameters for the crushing region around the dowel hole. To this end, relationships for the estimation of material characteristics as a function of the crushing volume are suggested. The validity and accuracy of the proposed modified foundation models are examined against the experimental results. It is shown the improved foundation model is able to simulate the embedment stiffness, capacity and inelastic behaviour of single-dowel connections on glulam with reasonable accuracy for strains of up to $8 \%$, and can therefore be used for design and assessment purposes.

\footnotetext{
${ }^{1}$ Email: c.malaga@imperial.ac.uk
} 


\section{Introduction}

2 Timber is an organic material made of cellulose fibres that exhibit complex mechanical behaviour.

3 The difficulties associated with modelling the response of structural wood are accentuated when

4 dealing with the behaviour of timber joints due to the intricate and highly non-linear interactions

5 between the different connection components. Nevertheless, knowledge of the behaviour of timber

6 joints is of paramount importance since they can govern the overall structural response and design.

7 In this context, single-dowel connections constitute a common and basic component of timber 8 joints. Therefore, to successfully design and assess timber joint details, accurate and reliable

9 mechanical or Finite Element (FE) numerical models of single-dowel connections are required. In this context, orthotropic material theory has been successfully incorporated into FE simulations within the linear-elastic range. Nevertheless, more advanced methods are required to deal with the localized nonlinear behaviour of timber such as that arising from embedment effects.

Patton-Mallory et al. [1,2], implemented an orthotropic constitutive law for timber (Douglas-fir) in the commercial software ABAQUS [3] incorporating a tri-linear stress-strain compression response parallel to grain. The proposed model was able to simulate the experimental results but with a marked tendency towards a numerically stiffer response. Importantly, only compression parallel-tograin was considered. Moses and Prion [4], studied the three-dimensional non-linear behaviour of a single-dowel timber connection test by means of a material model based on orthotropic elasticity and anisotropic plasticity together with the Weibull Weakest Link Theory to account for brittle failure. A good level of agreement between the numerically predicted force-displacement relationships and their corresponding experimental results was achieved. However, the estimation of ultimate loads was found to be over-conservative. Kharouf et al. [5] modelled bolted timber joints by assuming an elastic-plastic orthotropic Hill criterion for wood in compression and a linearelastic orthotropic criterion for wood in tension. The model was able to reproduce the 
experimentally observed failure modes and global deformation patterns in one-bolt joints but with a numerical stiffness significantly larger than the experimental values.

In general, the computational implementation of advanced failure criteria, such those reported in the above-cited studies, is highly complex and requires knowledge of advanced programming. Moreover, the difficulties associated with the definition of interactive failure modes and localized non-linear deformations further complicate their adoption. To this end, Fochi [6] proposed an approximate numerical two-dimensional model that takes into account the crunching behaviour of wood around the dowel by incorporating an equivalent circular area centred around the dowel with weakened material properties known as the 'foundation model'. More recently, Hong [7] extended the 'foundation' approach to three-dimensional continuum FE models representing bolted connections in Douglas-fir wood. Nevertheless, the dependence of the equivalent material properties on the volume assumed for the foundation zone was not investigated.

This paper revisits the foundation model for the simulation of the embedment behaviour in Scandinavian Spruce (Picea abies) with dowels. First, the results of an experimental campaign including compression, shear and embedment tests in the two main orientations with respect to the grain direction (perpendicular and parallel) are presented. The use of non-contact strain field measurements (DIC - Digital Image Correlation) to investigate the deformations around the embedding dowel is summarized. Particular attention is paid to the difference in the evolution of stress localization brought about by the different orientations of grain. Finally, a Modified Foundation Model is proposed for which relationships between equivalent material characteristics such as strength and stiffness as a function of the crushing volume are developed. In general, the improved foundation model proposed is able to simulate the embedment stiffness, capacity and inelastic behaviour of single-dowel connections on glulam with reasonable accuracy when 
compared with the experimental results.

\section{Material characterization}

4 This section presents the results of a detailed material characterization programme involving 5 twenty-five (25) Scandinavian Spruce Glulam specimens subjected to shear loads and compression 6 (parallel and perpendicular to grain). The tests were performed in accordance with European 7 standard EN 408 [8]. Mean values of compressive strength in each of the principal directions as 8 well as their corresponding shear resistance and Young's Moduli were obtained and are 9 summarized below. The species of the wood used was Scandinavian spruce (Picea Abies), with a mean density $\rho=430 \mathrm{~kg} / \mathrm{m}^{3}$ and a moister content of approximately $10 \%$. All the specimens were stored in a dry environment with mean temperature $20{ }^{\circ} \mathrm{C}$ and a relative humidity of $60 \%$.

(1)

\subsection{Compressive resistance}

4

A total of eight wood cubes of $45 \mathrm{~mm} \times 45 \mathrm{~mm} \times 45 \mathrm{~mm}$ were tested under compression parallel to the grain direction. A monotonically increasing load was applied to the specimen at a rate of 1 $\mathrm{mm} / \mathrm{min}$ as depicted in Figure 1. The applied load was measured with an accuracy of $\pm 0.1 \mathrm{kN}$ by means of the load cell incorporated within the testing apparatus. Table 1 summarizes the dimensions and mean response parameters obtained from the compression tests parallel to the grain together with their related coefficients of variation (COV), whereas Figure 2 presents the corresponding stress-strain relationships. 


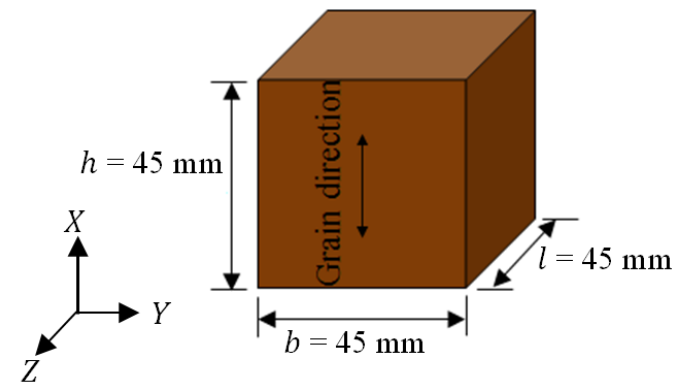

a) Specimen dimensions

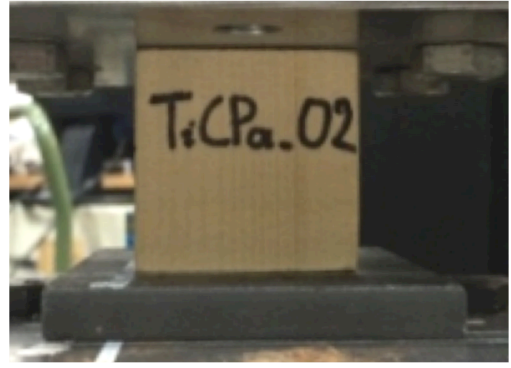

b) Test set-up

Figure 1. Compression tests parallel to grain.

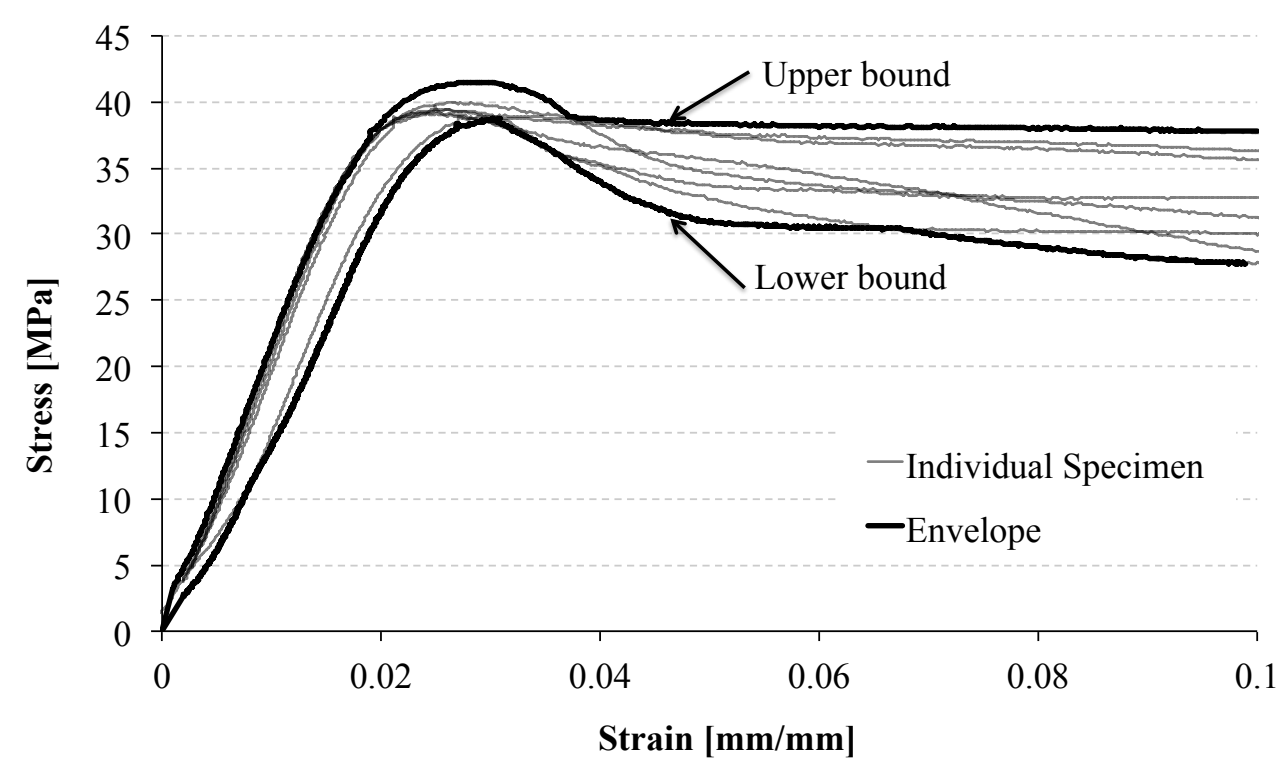

3 4 5

\begin{tabular}{|l|c|c|l|l|}
\hline Specimen & $\mathrm{A}\left[\mathrm{mm}^{2}\right]$ & $\mathrm{h}[\mathrm{mm}]$ & $\begin{array}{l}\text { Compressive } \\
\text { strength } \\
\sigma_{\mathrm{c}, 0, \mathrm{Ti}}[\mathrm{MPa}]\end{array}$ & $\begin{array}{l}\text { Young's } \\
\text { Modulus } \\
\mathrm{E}_{\mathrm{c}, 0, \mathrm{Ti}}[\mathrm{MPa}]\end{array}$ \\
\hline Average & 2023.2 & 45.2 & 39.6 & 2050.8 \\
COV [\%] & 0.6 & 0.4 & 2.0 & 14.0 \\
\hline
\end{tabular}

Table 1. Dimensions and characteristic parameters for Scandinavian Spruce glulam under 
2 The mean compressive strength parallel to the grain, $\sigma_{c, 0, T i}$ reported in Table 1 was obtained by 3 averaging the maximum strength values of each individual response. Similarly, the Elastic

4 Modulus, $E_{c, 0, T i, i}$, of specimen $i$ was estimated as:

$$
E_{C, 0, T i, i}=\frac{\left(0.4 F_{c, 0, T i, \max , i}-0.1 F_{c, 0, T i, \max , i}\right) h_{i}}{\left(u_{0.4, i}-u_{0.1, i}\right) A_{i}}
$$

where, $F_{c, 0, T i, \max , i}$ is the maximum compressive load reached by the timber specimen parallel to the grain, $A_{i}$ is the area under stress, $h_{i}$ is the specimen height (see Figure 1), and $u_{0.1, i}$ and $u_{0.4, i}$ are deformation increments corresponding to $10 \%$ and $40 \%$ of $F_{c, 0, T i, \max , i}$, respectively.

9

In addition to the material characterization tests in the direction parallel to grain described above, nine tests on wood specimens subjected to compression perpendicular to the grain were also carried out. The perpendicular-to-grain specimens had dimension of $45 \mathrm{~mm} \times 70 \mathrm{~mm} \times 90 \mathrm{~mm}$ as illustrated in Figure 3. This figure also presents the final test set-up employed. As before, the axial load was incrementally increased at a rate of $1 \mathrm{~mm} / \mathrm{min}$ and measured with an accuracy of \pm 0.05 mm. Figure 4 shows the results obtained from all compression tests perpendicular to the grain direction while Table 2 summarizes the corresponding dimensions and response parameters as well as their coefficient of variation (COV). It can be appreciated from Figure 4 that plastic deformations start to accumulate at low deformation levels (approximately 0.02 strain or $2 \mathrm{~mm}$ of vertical deformation) after which noticeable hardening occurs. Importantly, all specimens experienced a significant densification of the material for strains of approximately $0.2(18 \mathrm{~mm})$ during testing

The Elastic Modulus in compression perpendicular to the grain for specimen $i, E_{c, 90, T i, i}$, was calculated as:

$$
E_{c, 90, T i, i}=\frac{\left(0.4 F_{C, 90, T i, \max , i}-0.1 F_{c, 90, T i, \max , i}\right) h_{i}}{\left(u_{0.4, i}-u_{0.1, i}\right) A_{i}}
$$


1 where, $F_{c, 90, T i, \max , i}$ is the maximum compressive load reached by the timber sample, $A_{i}$ is the area 2 under stress, $h_{i}$ is the specimen height (see Figure 3), and $u_{0.1, i}$ and $u_{0.4, i}$ are deformation 3 increments corresponding to $10 \%$ and $40 \% F_{c, 90, T i, \max , i}$, respectively.

4

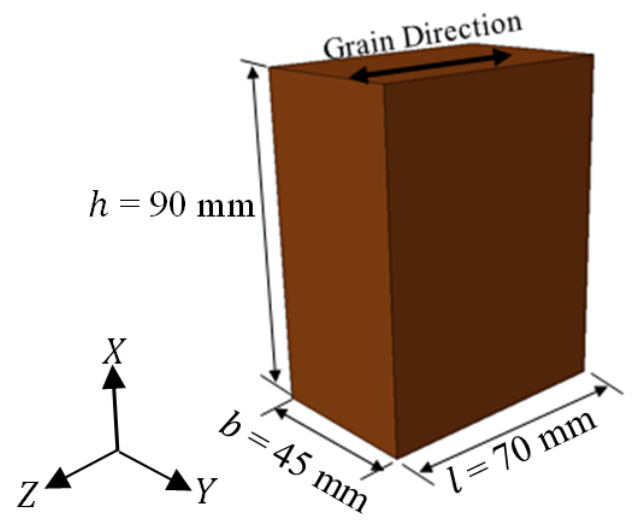

a) Specimen dimensions

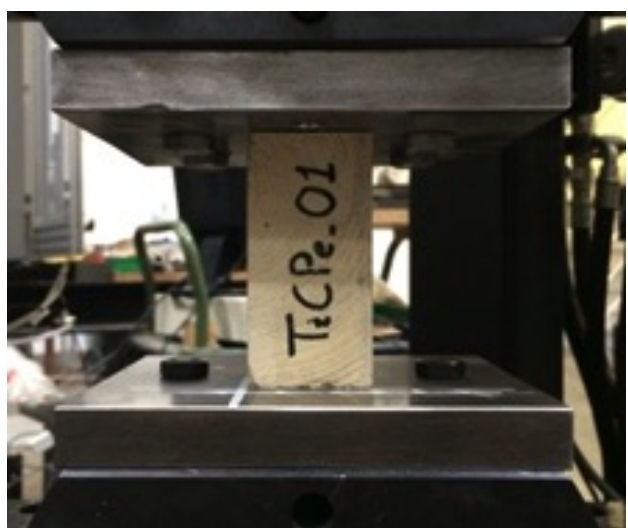

b) Test set-up

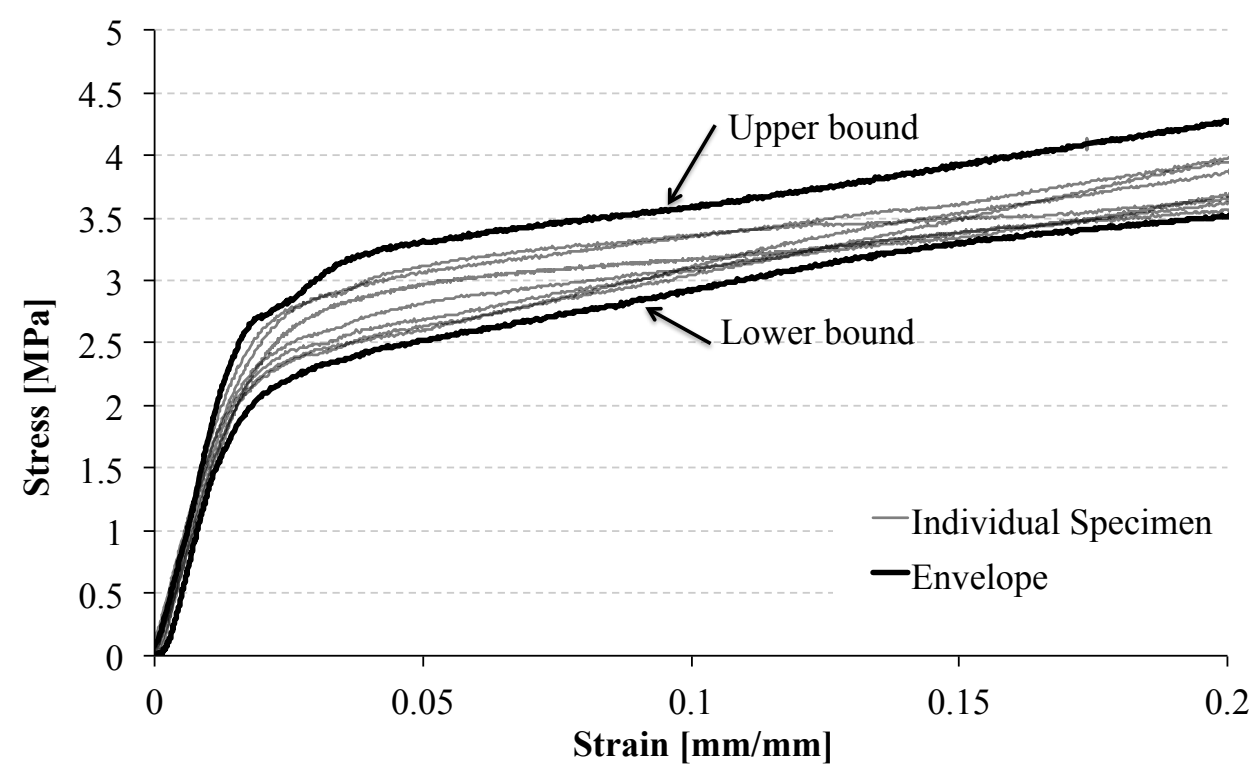

7 Figure 4. Compression stress-strain relationships for Scandinavian Spruce Glulam perpendicular to the direction of the grain 


\begin{tabular}{|l|c|c|c|c|}
\hline Specimen & $\mathrm{A}\left[\mathrm{mm}^{2}\right]$ & $\mathrm{h}[\mathrm{mm}]$ & $\begin{array}{c}\text { Compressive strength } \\
\sigma_{\mathrm{c}, 90, \mathrm{Ti}}[\mathrm{MPa}]\end{array}$ & $\begin{array}{c}\text { Young's Modulus } \\
\mathrm{E}_{\mathrm{c}, 90, \mathrm{Ti}}[\mathrm{MPa}]\end{array}$ \\
\hline Average & 3082.1 & 89.9 & 2.5 & 172.1 \\
COV $[\%]$ & 0.2 & 0.2 & 8.5 & 9.5 \\
\hline
\end{tabular}

Table 2. Dimensions and characteristic parameters for Scandinavian Spruce glulam under compression perpendicular to grain.

\subsection{Shear resistance}

Characterization of the shear strength of the wood employed in this study followed the European Standard EN408 [8]. To this end, eight specimens of $55 \mathrm{~mm} \times 32 \mathrm{~mm} \times 300 \mathrm{~mm}$ were manufactured and subjected to shear forces as showed in Figure 5. Two $10 \mathrm{~mm}$ thick steel plates were glued to each side of the specimen by means of a high strength high peel epoxy adhesive. The specimen was supported at an angle of $14^{\circ}$ with respect to the vertical axis of the actuator with the help of full-contact metallic stands. A monotonically increasing vertical load, F, was applied at a constant rate of $0.4 \mathrm{~mm} / \mathrm{min}$.

Table 3 reports the obtained mean values and COV while Figure 6 presents the results in terms of shear force versus engineering shear strain curves. The shear strength of each specimen was calculated as:

$$
\sigma_{v, 0, T i, i}=\frac{F_{v, 0, T i, \max , i}\left(\cos 14^{\circ}\right)}{A_{i}}
$$

where, $F_{v, 0, T i, \max , i}$ is the maximum compressive load reached and $A_{i}$ is the area under stress $\left(h_{i}\right.$. $\left.l_{i}\right)$. 


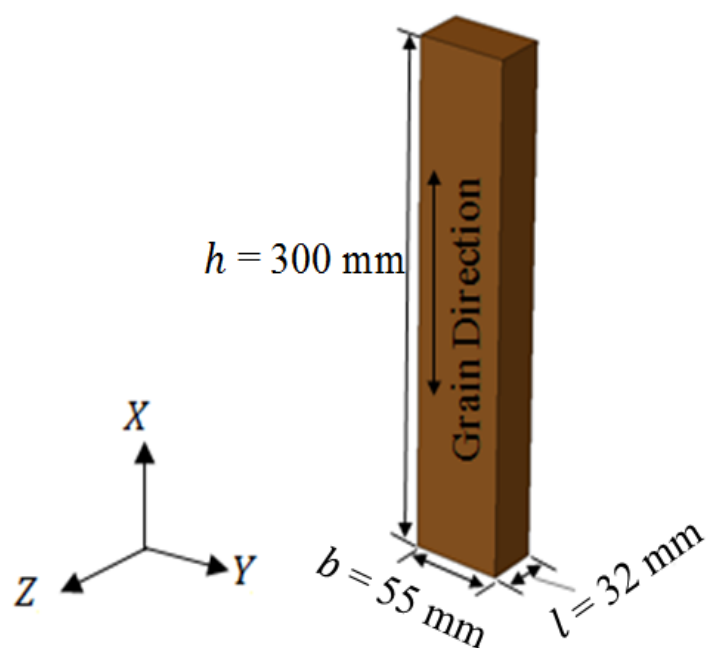

a) Specimen dimensions

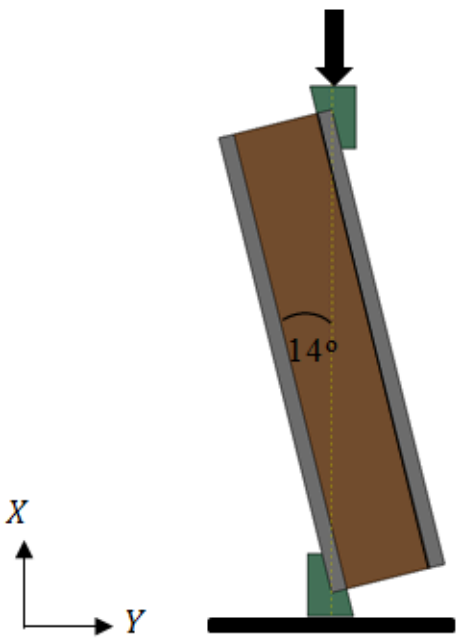

b) Test set-up

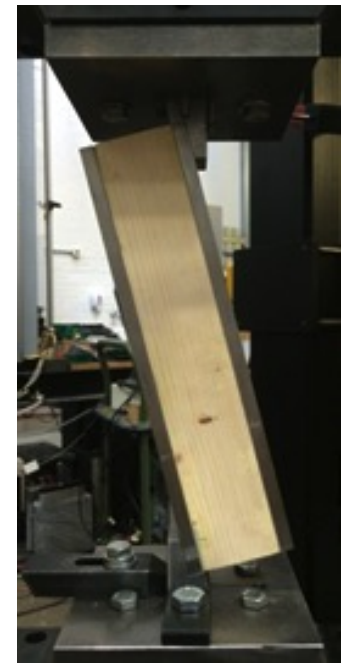

c) View of the experiment

Figure 5. Shear test.

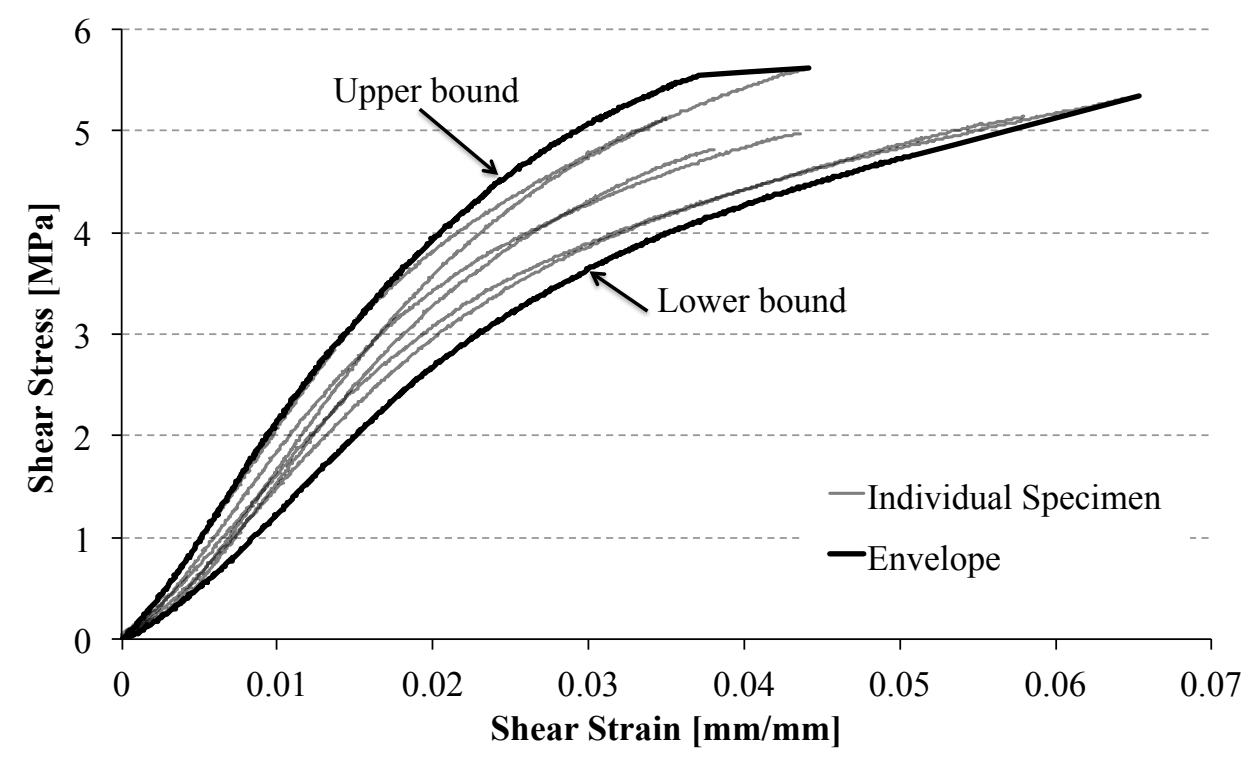

Figure 6. Shear force-displacement relationships for Scandinavian Spruce Glulam.

4

\begin{tabular}{|l|c|c|c|c|}
\hline Specimen & $\mathrm{A}\left[\mathrm{mm}^{2}\right]$ & $\mathrm{b}[\mathrm{mm}]$ & $\begin{array}{l}\text { Shear strength } \\
\sigma_{\mathrm{v}, 0, \mathrm{Ti}}[\mathrm{MPa}]\end{array}$ & $\begin{array}{l}\text { Shear Modulus } \\
\mathrm{G}_{12, \mathrm{Ti}}[\mathrm{MPa}]\end{array}$ \\
\hline Average & 9651.7 & 54.8 & 5.0 & 192.3 \\
COV [\%] & 0.3 & 0.4 & 5.9 & 12.3 \\
\hline
\end{tabular}

Table 3 - Summary of test results for glulam timber specimens under shear loads. 


\section{Embedment tests}

A total of thirty-seven (37) embedment tests were conducted including load directions parallel and

4 perpendicular to the grain. Two dowel diameters, $d=12 \mathrm{~mm}$ and $\mathrm{d}=16 \mathrm{~mm}$, were employed. The

5 tests were carried out in accordance with the European EN 383 Specification [9]. Figure 7 shows a

6 typical view of an embedment test with load acting parallel to the wood grain direction. Tests were

7 conducted on twelve specimens with $12 \mathrm{~mm}$ steel dowels and eight specimens with a $16 \mathrm{~mm}$

8 dowels. All dowels were made of high strength steel of Grade 10.9. A constant rate of $1 \mathrm{~mm} / \mathrm{min}$

9 was applied to the dowels by means of a purpose-built metallic assembly consisting of two steel side plates $100 \mathrm{~mm}$ wide and $20 \mathrm{~mm}$ thick welded and bolted together via a spacer steel block. The load and displacement at the centreline of the dowel were constantly recorded with accuracies of \pm $0.1 \mathrm{kN}$ and $\pm 0.05 \mathrm{~mm}$, respectively.

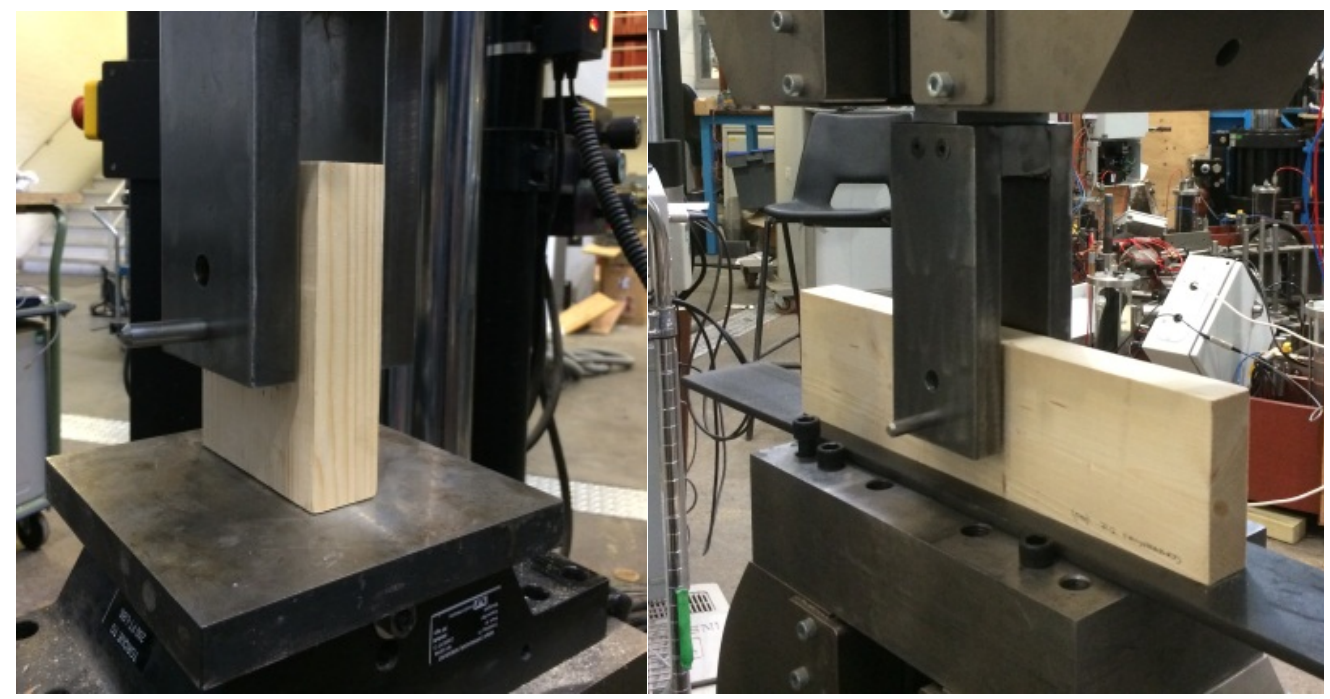

Figure 7. Experimental set-up of one-dowel connection test parallel to grain (left) and perpendicular to grain (right) for $12 \mathrm{~mm}$ dowels. 
10

\section{.}

\subsection{Mean values of strength and stiffness}

Tables 4 and 5 below, summarize the results of embedment tests performed in the parallel and perpendicular-to-grain directions, respectively. These tables include the number of specimens, specimen dimensions, mean embedment strength, mean embedment Elastic modulus and their corresponding coefficients of variation (COV). A bi-linear approximation was employed to calculate the values of strength and Elastic modulus reported in Tables 4 and 5. To this end, elasticplastic relationships were obtained by employing two lines tangent to the elastic and post-elastic branches of the experimental force-displacement curves as depicted in Figure 8. Accordingly, the embedment stress $\sigma_{a, E m b}$ and Elastics modulus $E_{a, E m b}$ for each specimen can be determined as:

$$
\sigma_{a, E m b}=\frac{F_{y, a, e m b}}{d \times t}
$$

$$
E_{a, E m b}=\frac{k_{a, e m b}}{t}
$$

where $F_{y, a, e m b}$ is the embedment force at the yield point, $u_{e m b}$ is the embedment in the timber in [mm], $k_{a, e m b}$ is the slope of the force-embedment curve in the linear-elastic region in $[\mathrm{kN} / \mathrm{mm}]$ and $d$ and $t$ are the dowel diameter and specimen width in [mm], respectively.

\begin{tabular}{|c|c|c|c|c|c|c|c|}
\hline $\begin{array}{c}\mathrm{d} \\
{[\mathrm{mm}]}\end{array}$ & $\begin{array}{c}\text { Number of } \\
\text { specimens }\end{array}$ & $\begin{array}{l}\text { Width } \\
{[\mathrm{mm}]}\end{array}$ & $\begin{array}{c}\text { Height } \\
{[\mathrm{mm}]}\end{array}$ & $\begin{array}{l}\text { Thick } \\
{[\mathrm{mm}]}\end{array}$ & $\begin{array}{l}\text { Embedment } \\
\text { strength } \\
\sigma_{0, \mathrm{Emb}} \\
{[\mathrm{MPa}]}\end{array}$ & $\begin{array}{l}\text { Embedment } \\
\text { Elastic } \\
\text { modulus } \\
\mathrm{E}_{0, \mathrm{Emb}} \\
{[\mathrm{MPa}]}\end{array}$ \\
\hline \multirow{2}{*}{12} & 12 & $\begin{array}{c}\text { COV } \\
{[\%]}\end{array}$ & 0.1 & 0.1 & 0.5 & 7.9 & 15.4 \\
\hline \multirow{2}{*}{16} & 8 & $\begin{array}{c}\text { Mean } \\
\text { COV } \\
{[\%]}\end{array}$ & 160.0 & 224.2 & 40.5 & 29.6 & 1033.9 \\
\hline
\end{tabular}

Table 4. Summary of embedment tests under loads parallel to the direction of the grain. 


\begin{tabular}{|c|c|c|c|c|c|c|c|}
\hline $\begin{array}{c}\mathrm{d} \\
{[\mathrm{mm}]}\end{array}$ & $\begin{array}{c}\text { Number } \\
\text { of } \\
\text { specimens }\end{array}$ & $\begin{array}{c}\text { Width } \\
{[\mathrm{mm}]}\end{array}$ & $\begin{array}{c}\text { Height } \\
{[\mathrm{mm}]}\end{array}$ & $\begin{array}{c}\text { Thickness } \\
{[\mathrm{mm}]}\end{array}$ & $\begin{array}{c}\text { Embedment } \\
\text { strength } \\
\sigma_{90, \mathrm{mb}} \\
{[\mathrm{MPa}]}\end{array}$ & $\begin{array}{c}\text { Embedment } \\
\text { Elastic } \\
\text { modulus } \\
\mathrm{E}_{90, \mathrm{Emb}} \\
{[\mathrm{MPa}]}\end{array}$ \\
\hline \multirow{2}{*}{12} & 8 & $\begin{array}{c}\text { COV } \\
{[\%]}\end{array}$ & 0.1 & 0.3 & 0.9 & 11.9 & 30.7 \\
\hline \multirow{2}{*}{16} & 9 & Mean & 640.3 & 159.4 & 40.3 & 14.6 & 240.8 \\
\cline { 3 - 8 } & & $\begin{array}{c}\text { COV } \\
{[\%]}\end{array}$ & 0.1 & 0.1 & 0.5 & 17.2 & 7.1 \\
\hline
\end{tabular}

Table 5. Summary of embedment tests under loads perpendicular to the direction of the grain.

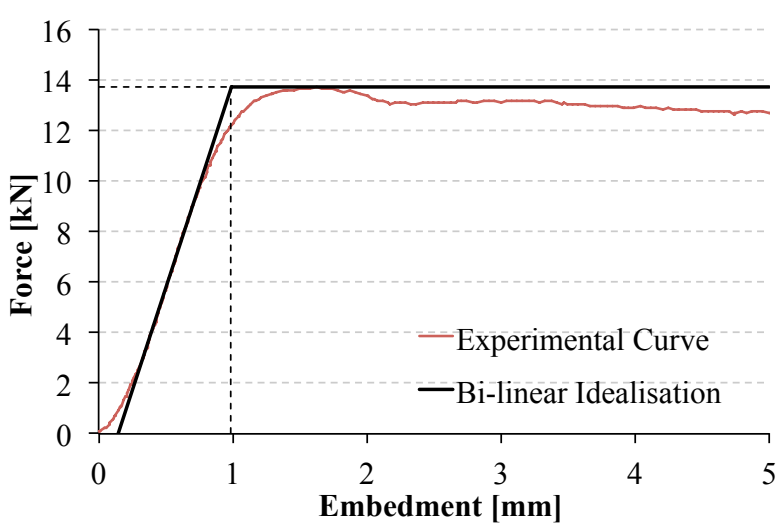

a) Parallel to grain

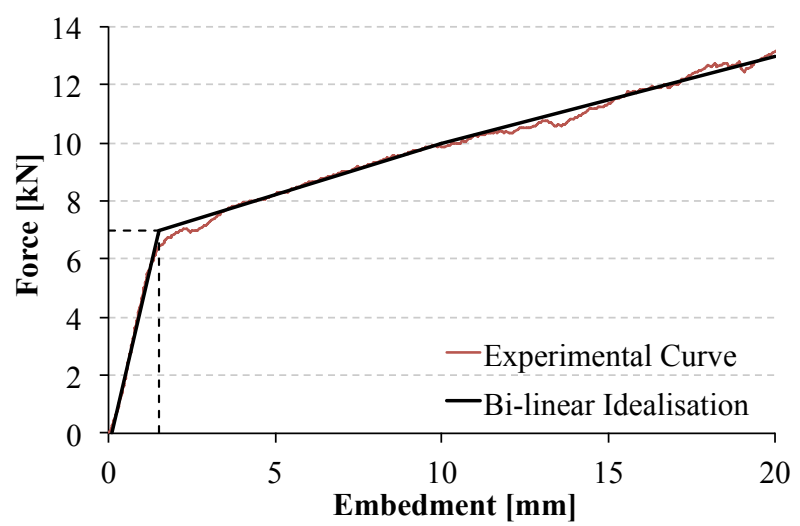

b) Perpendicular to grain

Figure 8. Typical experimental force-embedment curves and their corresponding bi-linear approximations (dowel diameter $\mathrm{d}=12 \mathrm{~mm}$ )

\subsection{Embedment response parallel to the grain direction}

Figure 9 shows the results obtained from the embedment tests on glulam with $12 \mathrm{~mm}$ and $16 \mathrm{~mm}$ dowels. An initial relatively flexible stage is evident from this figure for loads lower than $2 \mathrm{kN}$.

This behaviour is attributed to the non-uniform contact and initial clearance existing between the dowel and the timber material, which leads to the rapid accumulation of localized deformations. Once a uniform contact is attained along the full embedment width, a linear stage develops with forces increasing in direct proportion to the deformation until they reach the embedment strength of 
1 the specimen, after which a third behavioural stage develops. This final response stage corresponds to deformations greater than $0.8 \mathrm{~mm}$ and $0.5 \mathrm{~mm}$ embedment for 12 and $16 \mathrm{~mm}$ dowels, 3 respectively and is characterized by a largely plastic response as can be observed in Figure 9.

4

5 Mean embedment strength values of $29.4 \mathrm{MPa}$ and $29.6 \mathrm{MPa}$ are observed for the 12 and $16 \mathrm{~mm}$ doweled connections, respectively. These values can be compared to the embedment strengths assumed by Eurocode 5 [10] calculated as:

(1)

$$
\sigma_{0, E m b, D X, k}=0.082 \times(1-0.01 d) \rho
$$

where, $\sigma_{0, E m b, D X, k}$ is the characteristic embedment strength for $X$ dowel diameter, $d$ is the diameter of the dowel and $\rho$ is the density of the timber specimen. By introducing the corresponding values into Equation 7, mean characteristic embedment strengths of $31.1 \mathrm{MPa}$ and $30.2 \mathrm{MPa}$ are obtained for $12 \mathrm{~mm}$ and $16 \mathrm{~mm}$ dowels, respectively. These values are in close agreement with the experimentally obtained mean embedment resistances. Similarly, mean Young's modulus values of values of $376.0 \mathrm{MPa}$ and 1033.9 MPa were observed for the connections with $12 \mathrm{~mm}$ and $16 \mathrm{~mm}$ dowels, respectively. It is evident from the results reported in Figure 9 and Table 4 that the larger the dowel diameter the stiffer the response.

9




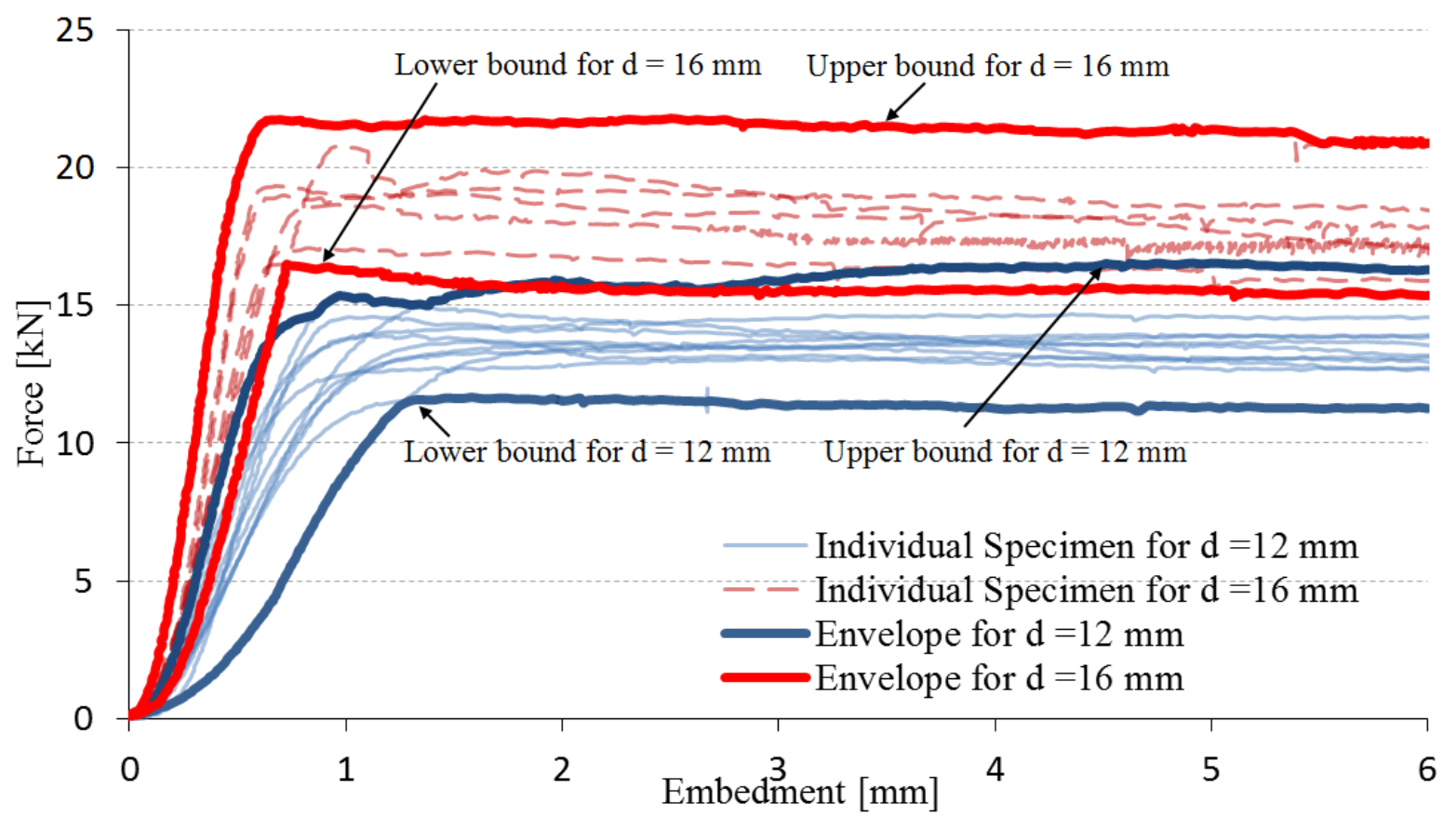

Figure 9. Force-embedment relationships in the direction parallel to grain.

\subsection{Embedment response perpendicular to the grain direction}

4 A total of eight tests were performed with a $12 \mathrm{~mm}$ diameter dowel pushed in the direction

5 perpendicular to the wood grain, while nine specimens were tested with a $16 \mathrm{~mm}$ diameter dowel. The experimental procedure followed was identical to the one previously described for embedment tests parallel to the grain direction. Figure 10 summarizes the results in terms of force-embedment curves while Table 5 presents the mean values and COV for strength and Elastic modulus. 


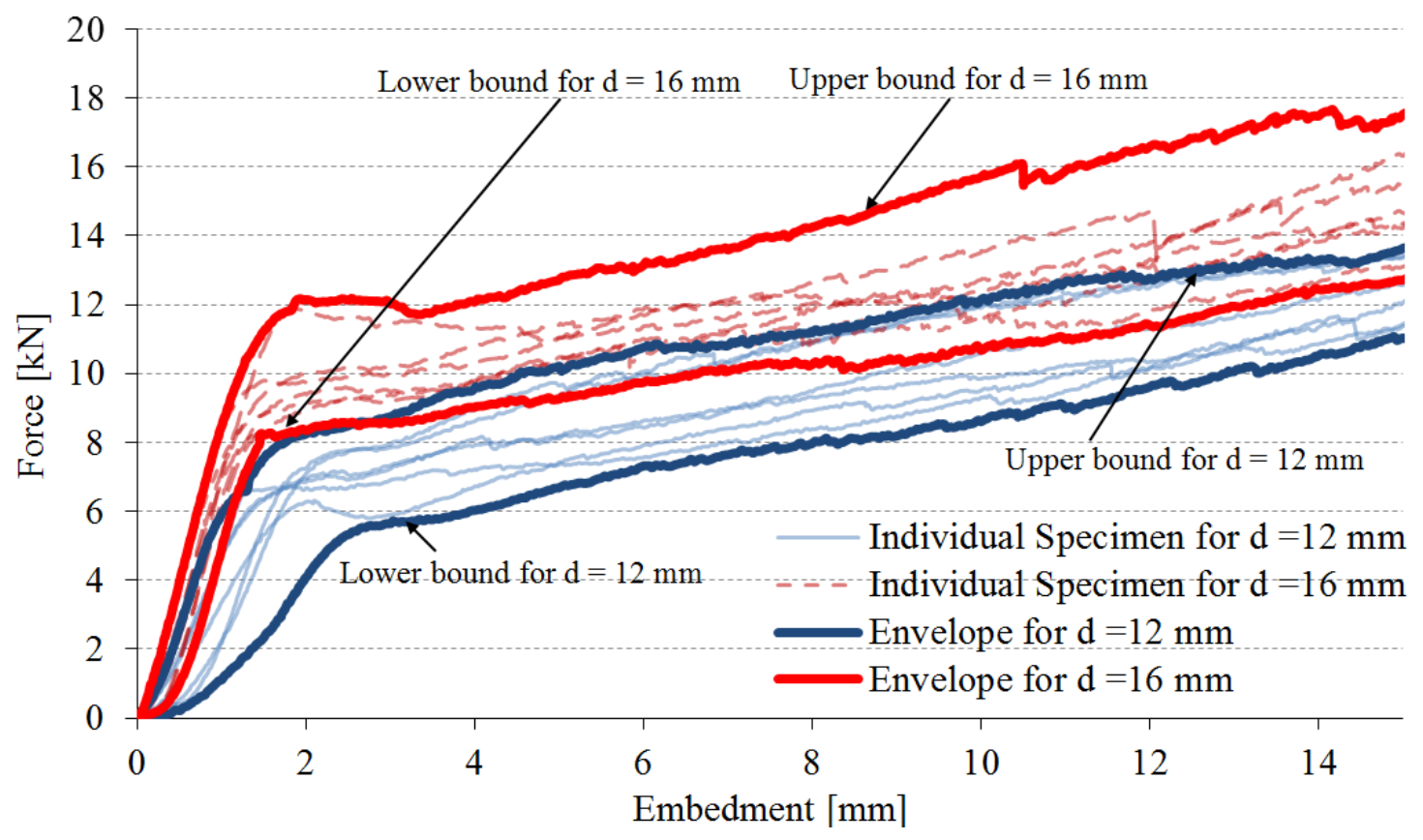

Figure 10. Force-embedment relationships in the direction perpendicular to grain.

2

3 The embedment behaviour in the direction perpendicular to the grain follows the general trends

4 already identified before for parallel-to-grain specimens where three behavioural stages are evident 
To investigate the localisation of strains around the embedment area, a LaVision [11] Digital Image

3 Correlation (DIC) system was employed. Two cameras were employed in order to reduce the

4 potential in-plane two-dimensional measurement errors associated with small out-of-plane motion.

5 A full description of the binocular stereovision principles on which the DIC technique is based is

6 outside the scope of the present study and more detailed information can be found elsewhere [12].

7 Figure 11 presents a view of the experimental set-up together with the DIC instrumentation utilized.

8 Two cameras spaced at $500 \mathrm{~mm}$ from each other were placed at a distance of $1200 \mathrm{~mm}$ from the

9 specimen. The cameras were rotated $15^{\circ}$ as presented in Figure 11. High quality images were 10 captured during the testing of the specimen at a rate of 31 frames per minute. Calibration of the 11 focus areas was conducted by means of a $200 \times 200 \mathrm{~mm}^{2}$ calibration plate while the specimens were prepared by spraying a randomized pattern of dots into the face where strains were to be measured. The DIC algorithm [13] tracks the motion of surface patterns during the experiment and calculates the corresponding $2 \mathrm{D}$ strain fields in each picture.

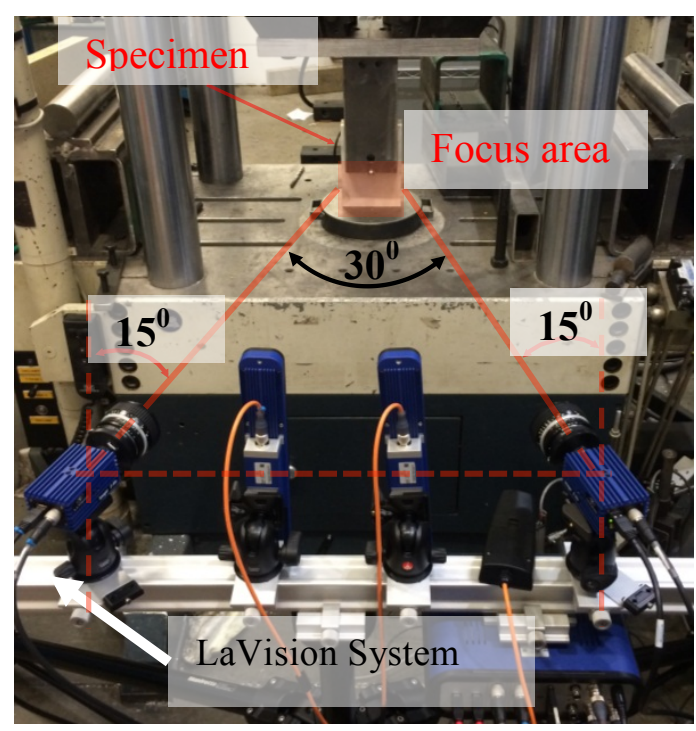

Figure 11. Experimental set-up with the DIC system. Embedment tests on a $12 \mathrm{~mm}$ dowel 
1 Figures 12 and 13 show typical relative deformation contours obtained by means of the DIC system previously described together with their corresponding force-embedment curves for parallel-to-

3 grain and perpendicular-to-grain specimens, respectively. Only the contours corresponding to the 4 left bottom quarter of the specimen, below the dowel hole, are presented due to symmetry. It is 5 evident from Figure 12, which presents the results for loading parallel to the grain, that as the embedment progresses, the area with largest relative displacement (shown in purple) also increases. Also, beyond $1.5 \mathrm{~mm}$ of embedment deformation, noticeable accumulation of localized damage around the dowel was evident during the experiment.

9

Contour plot area

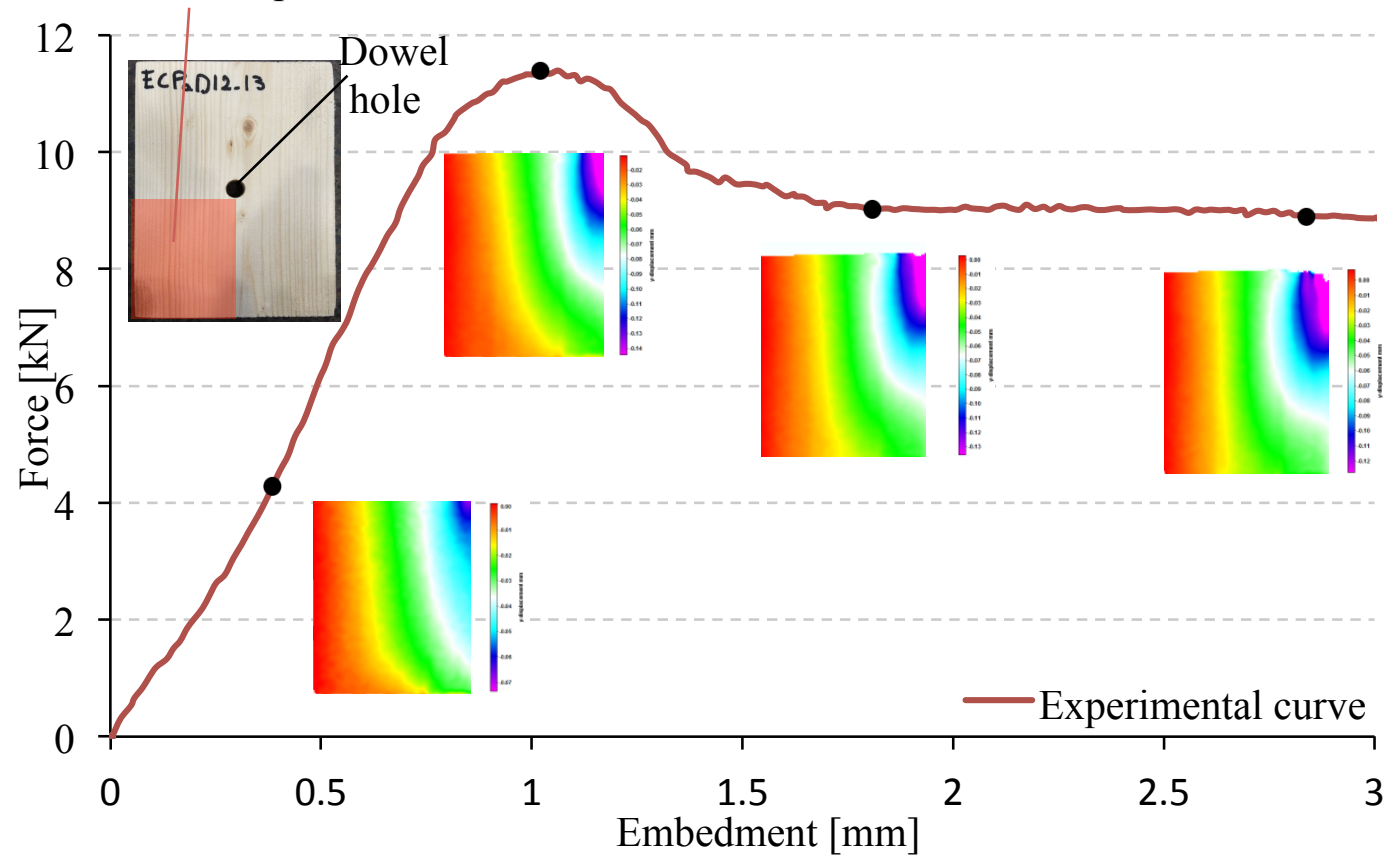

Figure 12. Force-embedment curve from the embedment test perpendicular to the grain $(\mathrm{d}=12 \mathrm{~mm})$

Similarly, Figure 13 shows the force-embedment curve together with the relative displacement contours at four key behavioural stages for a perpendicular-to-grain test that employs a $12 \mathrm{~mm}$ dowel. In this figure, the area of largest concentration of deformations (purple) decreases in size as the embedment increases while a more pronounced horizontal orientation of contours relative to Figure 12 is evident. 


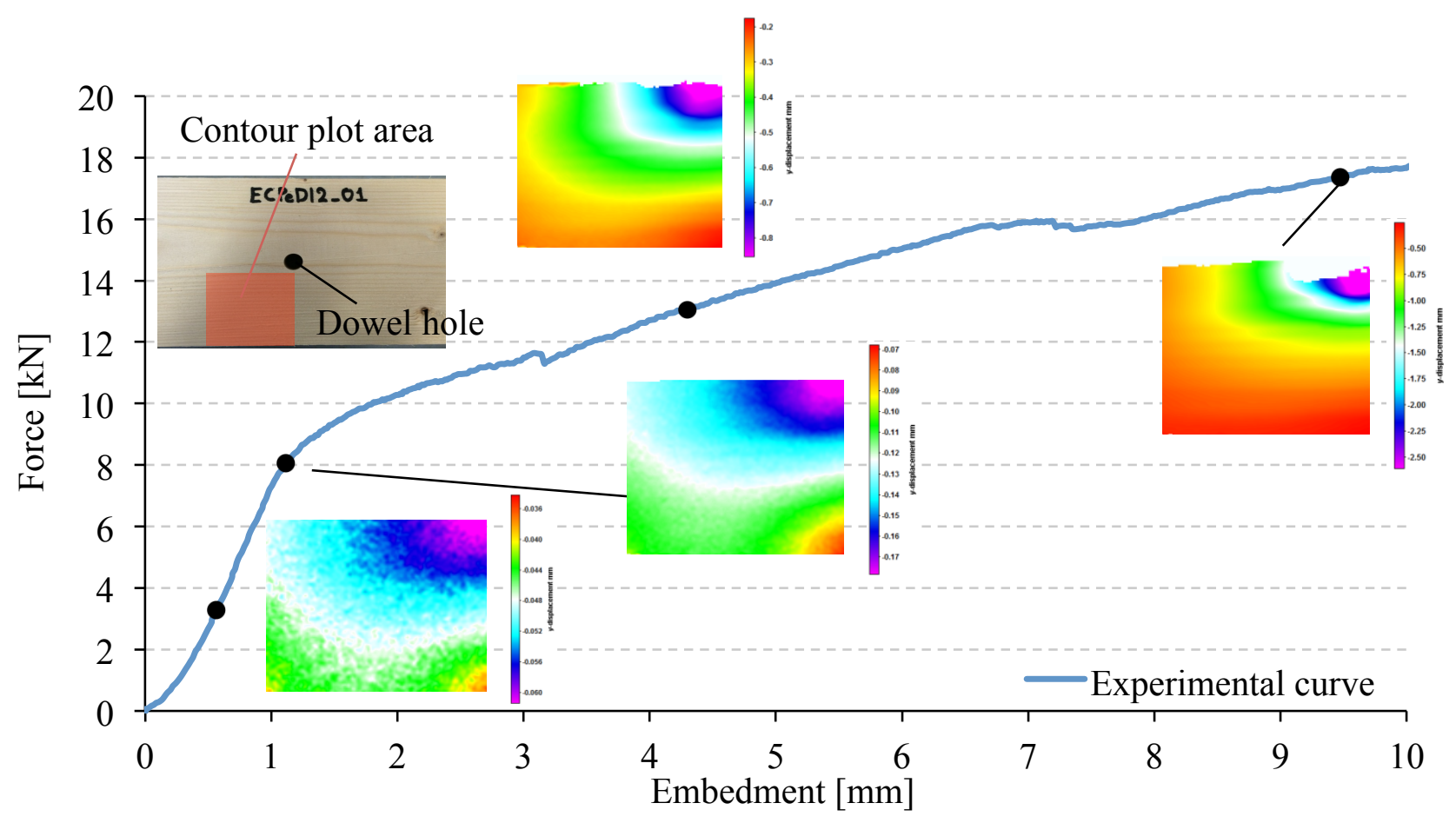

Figure 13. Force-embedment curve from the embedment test perpendicular to the grain $(\mathrm{d}=12 \mathrm{~mm})$

These differences in the evolution of areas of high deformation between parallel-to-grain (Figure 12) and perpendicular-to-grain (Figure 13) specimens can be attributed to the different mechanisms of load resistance involved as schematically shown in Figure 14. In parallel-to-grain loading, local buckling of some of the vertical fibres in direct contact with the dowel occurs at large deformation levels. With increasing demands, the confining action of the surrounding vertical fibres will favour a further concentration of deformation in the already buckled fibres directly below the dowel hence engaging more material underneath the dowel in the same direction of loading. On the other hand, when the action is applied perpendicular to the direction of the grain, the displacement of wood material tends to localize on the upper fibres with the lower fibres acting as an elastic foundation. This behaviour will encourage the concentration of non-linear response on the upper fibres once they have yielded while spreading the deformation field horizontally as observed in Figure 13. 


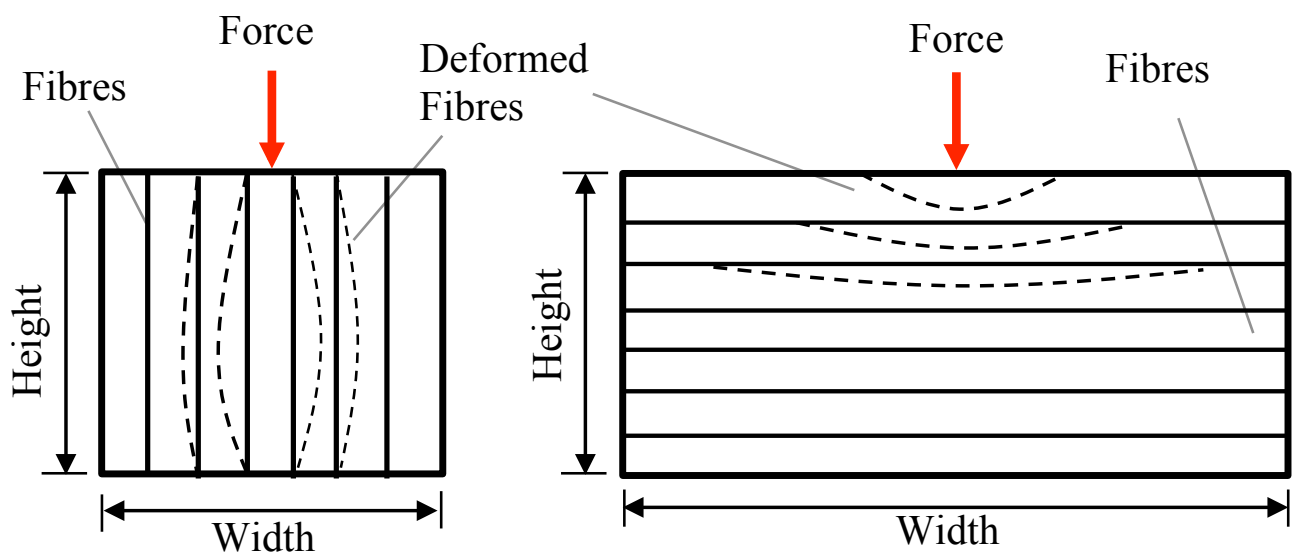

a) Parallel to grain

b) Perpendicular to grain

Figure 14. Interaction between the embedment force and the fibre orientation.

These differences in strain localization brought about by the changes in fibre orientation with respect to the direction of load application can be further studied with reference to Figures 15 and 16 which present the y-displacement contours at maximum embedment force for parallel-to-grain and perpendicular-to-grain specimens, respectively. It can be seen from these figures that the area under analysis is located $3 \mathrm{~mm}$ below the hole in the left-side of the YZ-symmetry plane. Similarly, it can be seen from the contour plots of Figures 15 and 16, that the vertical distance along which the greater concentration of displacements is located is approximately $20 \mathrm{~mm}$ when the maximum load is applied parallel to the grain direction (Figure 15) while it is half of this $(10 \mathrm{~mm})$ when the maximum load is applied perpendicular to the grain direction. The effects of grain orientation on the main directionality of the strain field are also evident from Figures 15 and 16 with the contours tending to follow the grain orientation over the whole strain field computed. Finally, it is worth noting that the maximum absolute values of y-displacement in Figures 15 and 16 are 0.15 and 0.18 $\mathrm{mm}$, respectively. This indicates that more than $80 \%$ of the total embedment displacement $(\sim 0.85$ $\mathrm{mm}$ for Figure 15 and $\sim 0.84 \mathrm{~mm}$ for Figure 16) is concentrated within the area in close proximity 
1 to the hole (e.g. within $3 \mathrm{~mm}$ from the dowel surface in the case of parallel to grain loading as 2 presented in Figure 15).

3

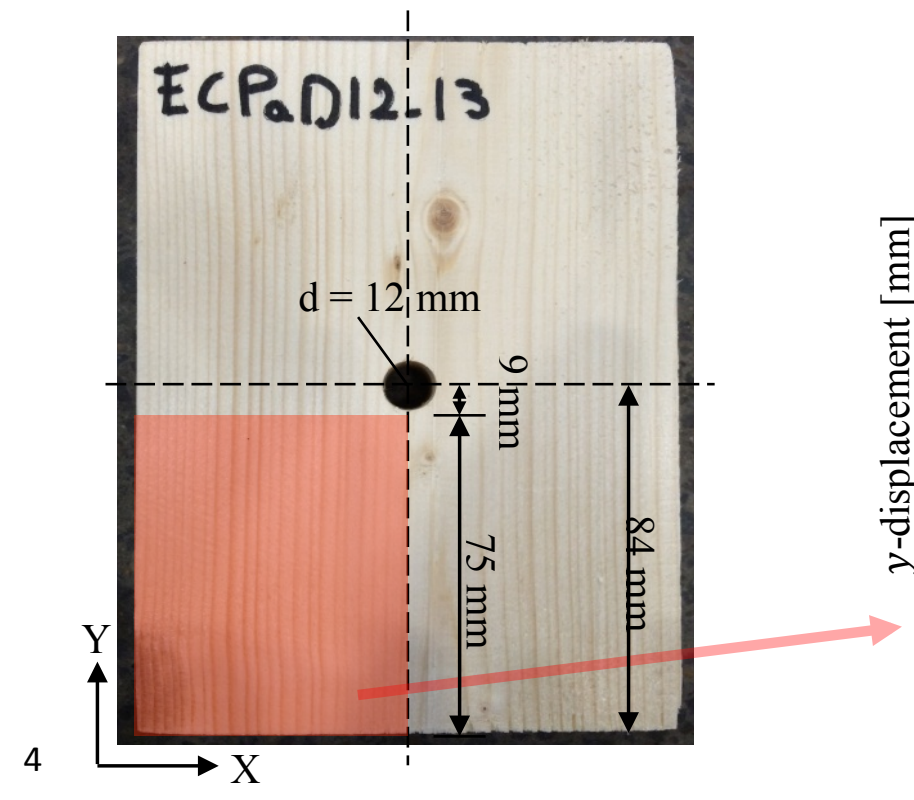

5

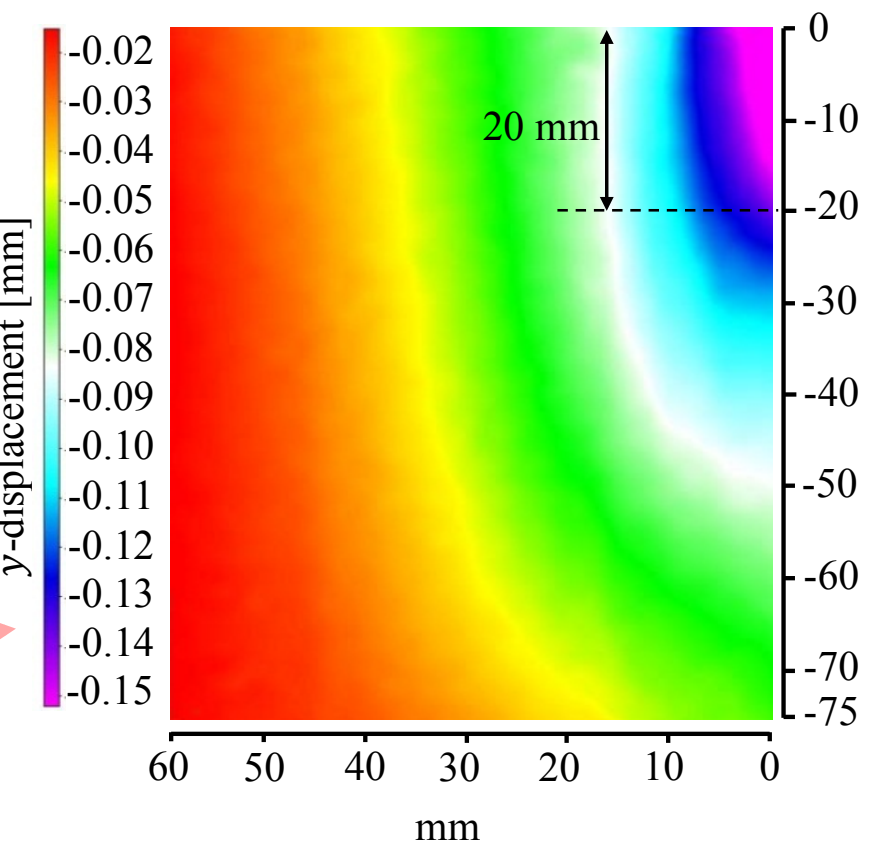

छ

Figure 15. Displacement contours of one-dowel connection test, parallel to grain with a $12 \mathrm{~mm}$ dowel at maximum embedment force $(\sim 1.0 \mathrm{~mm}$ of vertical displacement)

8

9

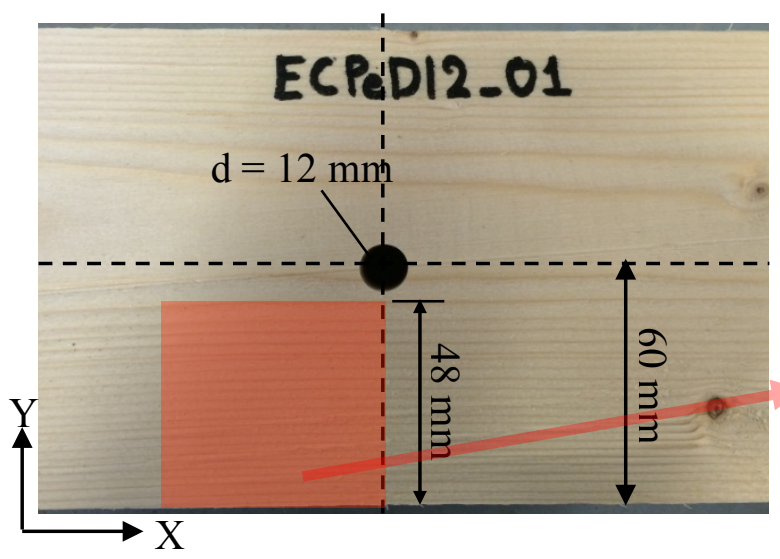

10
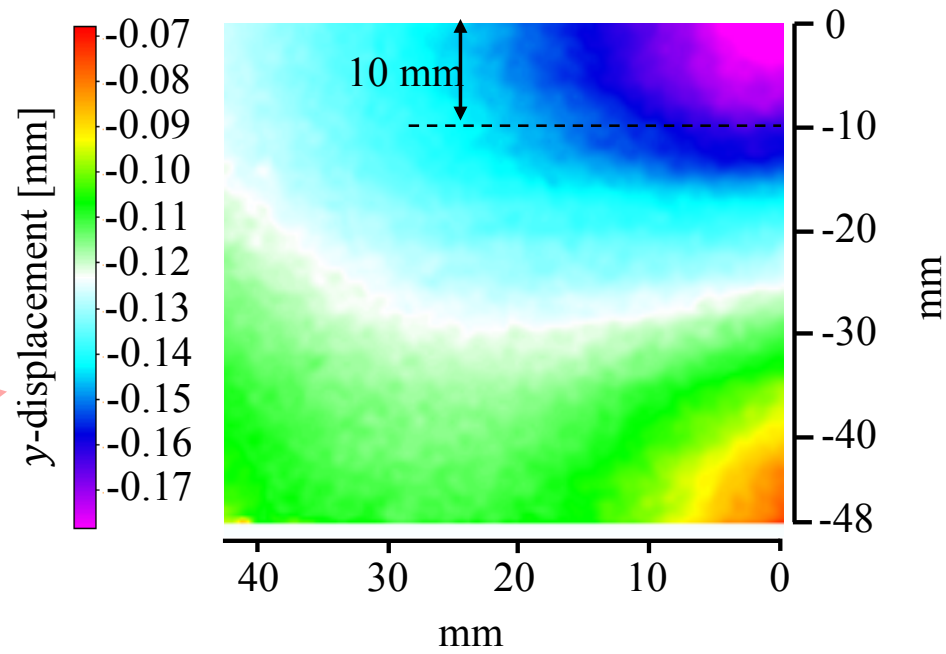

Figure 16. Displacement contours of one-dowel connection test, perpendicular to grain with a 12 $\mathrm{mm}$ dowel at the yield point ( $\sim 1.02 \mathrm{~mm}$ of vertical displacement) 


\section{Modified foundation model}

2 From the previous discussion, it can be appreciated that the response of dowel type connections is a 3 complex multi-dimensional problem for which modelling is not feasible through conventional 4 Finite Element (FE) programs by assuming standard or test-based material properties. This is

5 because conventional continuum FE programs lack the ability to simulate the intricate bearing 6 phenomena of the wood matrix. Figure 17 presents a typical comparison between a force7 embedment deformation response obtained by means of a FE model and its corresponding experimental results for a $12 \mathrm{~mm}$ diameter dowel. The FE simulation is based on a continuum FE representation of wood by means of an anisotropic yield criterion applied homogeneously throughout the specimen (i.e. no difference is made between the material characteristics of the main timber body and the zone surrounding the dowel as will be done later when a foundation zone is introduced). Besides, the experimental results are represented in Figure 17 by their corresponding upper and lower bound curves (or envelope) that mark the limits of the experimentally observed force-embedment responses. Significant differences between the predicted and observed response are evident from Figure 17. These differences, which are more apparent in the post-elastic range stem from the effects of the evolution of the area/volume of strain concentration around the hole

17 leading to a complex response as explained in the previous section. These intricacies in the mechanical behaviour of wood can be approximated in the FE simulation by incorporating a region around the hole with empirically calibrated material properties, which is referred herein as the 'foundation zone' [6]. 


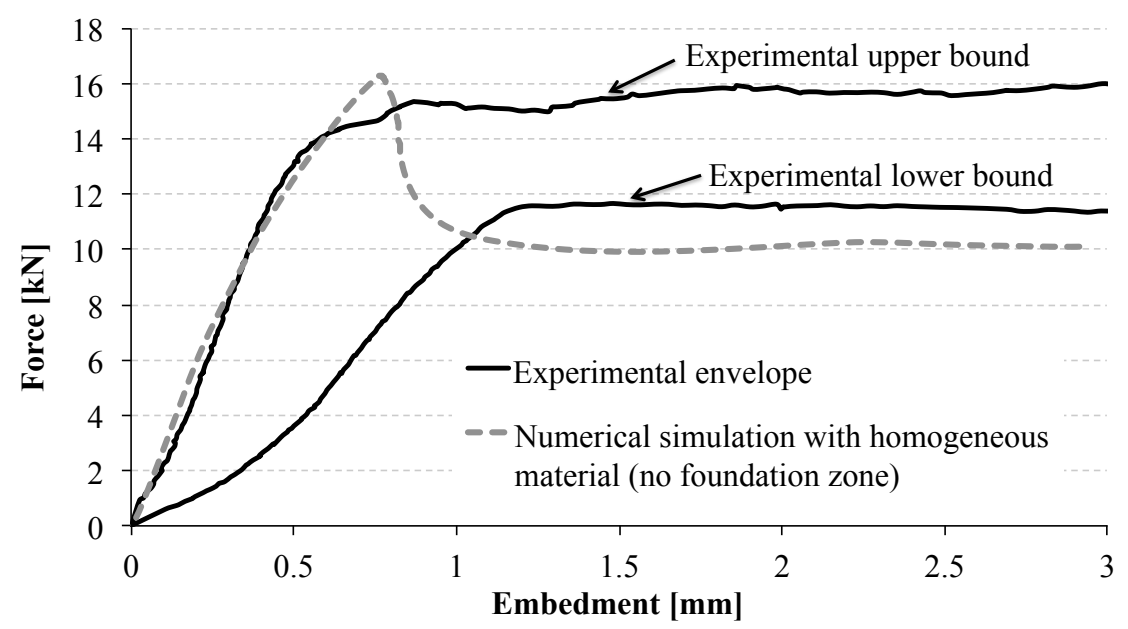

Figure 17. Comparison between experimental embedment force-displacement response and FE simulation for parallel to grain direction

In light of the above discussion, the foundation zone approach, initially proposed by Foschi [6] for Douglas-fir (Pseudotsuga menziesii) emerges as an alternative solution with the potential for incorporating the effects of localized wood crushing into a FE simulation in a simple yet effective way. Figure 18 depicts the FE implementation of the foundation model approach for the simulation of a single-dowel connection embedment response. The method hinges around the incorporation of a modified material model within a certain volume around the dowel hole. This volume is referred to as the foundation zone (presented in white in Figure 18) for which the properties are determined via calibration procedures. In its original form, the foundation model assumed a cylindrical volume with a constant radius of 2.8 times the dowel diameter. This value was selected on the basis of experimental constraints related to the maximum size of the specimen tested [6] and no rational justification was offered. Furthermore, no provision was made for the use of the method when alterative geometric constraints may govern the definition of the foundation zone dimensions. In this section, the foundation material model is modified and extended for the case of Scandinavian Spruce Glulam. Also, a non-arbitrary procedure for the definition of material parameters within the foundation zone as a function of its volume are discussed and implemented. 


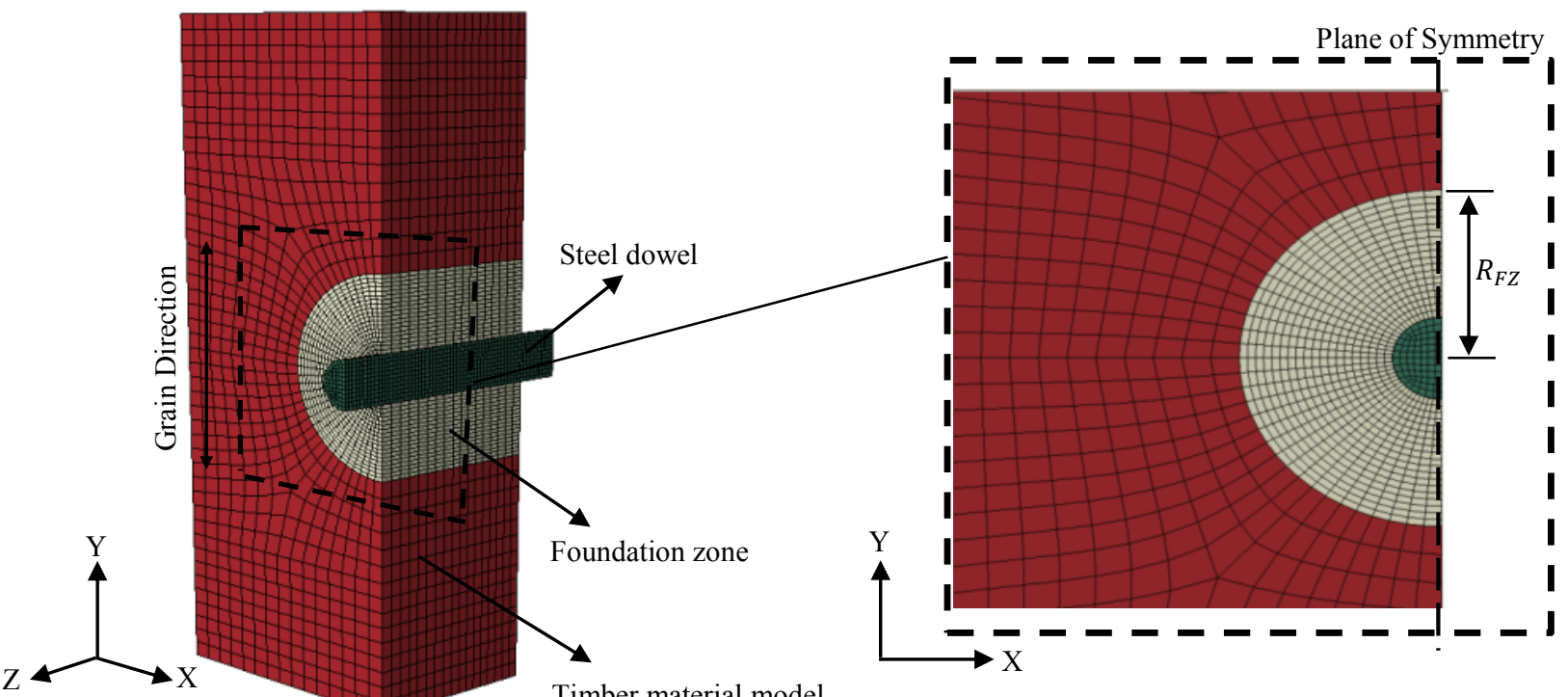

Figure 18. Implementation of a single-dowel foundation FE model

\subsection{Numerical modelling}

Detailed 3D models were constructed by means of the FE program ABAQUS V6.14 [15]. A typical model is illustrated in Figure 18. This model makes use of eight-node brick solid elements of Type C3D8. It can also be appreciated from Figure 18 that symmetry conditions were used in order to save computational resources. A tri-linear kinematic hardening representation with an elastic modulus of $210 \mathrm{GPa}$ and a Poisson's ratio of 0.3 was employed for the steel dowels. This steel stress-strain relationship incorporates an elastic stage, a constant stress plateau up to a strain level of approximately 0.01 , and a $1 \%$ strain-hardening stiffness thereafter. Importantly, all steel dowels remained elastic during the experiments and this was also reflected in the numerical simulations. Similarly, the experimentally obtained mean material properties described above were adopted for the wood. Modified values of strength and stiffness were employed for the wood within the foundation zone as described in the next section. 
1 Contact phenomena between steel and wood were modelled by defining pairs of "master" and "slave" contact surfaces in ABAQUS. To this end, the relatively more flexible wood surface was defines as "slave" whereas the stiffer steel dowel surface was chosen as "master". The hard contact over-closure pressure relationship of ABAQUS was modified by adopting a linear relationship with significantly stiff response to minimise non-convergence. A friction coefficient of $\mu=0.7$ was adopted as proposed by Smith [14]. The nodes at the two opposite ends of the dowel were progressively moved downwards along the $y$-axis and the corresponding vertical reaction forces at the base nodes were recorded.

A number of mesh size sensitivity studies were carried out in order to arrive at an optimum element size distribution. The adopted mesh arrangement involved a coarser mesh within the main body of the wood sample, whereas a finer mesh was employed for the foundation zone around the dowel hole. The dimensions of the finally adopted mesh ranged between $1 \mathrm{~mm}$ and $5 \mathrm{~mm}$

\subsection{Foundation zone material properties}

Mean material properties from the previously described testing campaign were adopted for the main wood volume (outside the foundation zone). On the other hand, relatively softer and weaker material parameters were adopted for the foundation zone. Table 6 presents the ratios between the material parameters as obtained from embedment tests (identified by the subscript $E m b$ ) and those measured from direct compression tests (identified by the subscript $m$ ) the indices 1 to 3 refer to the three principal stress directions. These ratios were employed to define a basic set of material parameters for the foundation region. In the case of Poisson ratios and shear strengths, nominal values were assumed regardless of the foundation zone distinction. Similarly, the values for the shear modulus $G$ introduced into the foundation zone were estimated from the empirical formula given in the annex of EN 338:2009 [16] as: 


$$
\mathrm{G}_{12}=\frac{\mathrm{E}_{11}}{16}
$$

\begin{tabular}{|c|c|c|}
\hline & $\mathrm{d}=12 \mathrm{~mm}$ & $\mathrm{~d}=16 \mathrm{~mm}$ \\
\hline$E_{1, E m b} / E_{1, m}$ & 0.183 & 0.504 \\
\hline$E_{2, E m b} / E_{2, m}=E_{3, E m b} / E_{3, m}$ & 0.795 & 1.398 \\
\hline$G_{12, E m b} / G_{12, m}=G_{13, E m b} / G_{13, m}$ & 0.122 & 0.122 \\
\hline$G_{23, E m b} / G_{23, m}$ & 0.0122 & 0.0122 \\
\hline$\sigma_{11, E m b} / \sigma_{11, m}$ & 0.743 & 0.746 \\
\hline$\sigma_{22, E m b} / \sigma_{22, m}=\sigma_{33, E m b} / \sigma_{33, m}$ & 5.795 & 5.748 \\
\hline
\end{tabular}

Table 6 - Material properties for the foundation modelling approach.

6 The original foundation zone approach for 3D models as proposed by Hong [7] assumes a constant radius $R_{F Z}=1.4 d$ for the foundation zone thus disregarding any variation in the definition of a

8 weakened volume and its effects on the corresponding weakened material characteristics. This can

9 limit the applicability of the method when the connection to be modelled is part of a different

$$
R_{F Z}=P \cdot d
$$

Furthermore, on the basis of extensive parametric analyses, the following expressions are proposed herein for the determination of effective Elastic Modulus within the foundation zone in the directions parallel $\left(E_{1, F Z}\right)$ and perpendicular $\left(E_{2, F Z}\right)$ to the grain direction: 


$$
E_{1, F Z}=\left(1+\beta_{1} \frac{P}{t}\right) E_{1, E m b}
$$

$$
E_{2, F Z}=\left(1+\beta_{2} \frac{P}{t}\right) E_{2, E m b}
$$

4

5 where, $t$ is the thickness of the specimen in [mm], $E_{E m b}$ is the Young's modulus determined from 6 the embedment tests in [MPa], $E_{F Z}$ is Young's modulus of the foundation zone in [MPa] and $\beta_{1}$ 7 and $\beta_{2}$ are empirical parameters for which optimal values are reported in Table 7 below

8

\begin{tabular}{|c|c|c|}
\hline Parameter & $\mathrm{d}=12 \mathrm{~mm}$ & $\mathrm{~d}=16 \mathrm{~mm}$ \\
\hline$\beta_{1}$ & 6.27 & 2.28 \\
\hline$\beta_{2}$ & 5.51 & 3.13 \\
\hline
\end{tabular}
mm dowels.

4

Table $7-$ Values for parameters $\beta_{1}$ and $\beta_{2}$ as a function of the dowel diameter.

Similarly, the following expressions are proposed for the estimation of yield stresses in the directions parallel $\left(E_{1, F Z}\right)$ and perpendicular $\left(E_{2, F Z}\right)$ to the grain direction:

where, $t$ is the thickness of the specimen in [mm], $d$ is the diameter of the dowel in [mm], $\sigma_{E m b}$ is the stress determined from the embedment tests in $[\mathrm{MPa}], \sigma_{F Z}$ is the stress of the foundation zone in [MPa] and $\gamma_{1}$ and $\gamma_{2}$ are parameters for which values can be found in Table 8 for $12 \mathrm{~mm}$ and 16

$$
\begin{aligned}
& \sigma_{11, F Z}=\left(1-\gamma_{1} \frac{P}{d \cdot t}\right) \sigma_{11, E m b} \\
& \sigma_{22, F Z}=\left(1-\gamma_{2} \frac{P}{d \cdot t}\right) \sigma_{22, E m b}
\end{aligned}
$$




\begin{tabular}{|c|c|c|}
\hline Parameter & $\mathrm{d}=12 \mathrm{~mm}$ & $\mathrm{~d}=16 \mathrm{~mm}$ \\
\hline$\gamma_{1}$ & 14.67 & 14.60 \\
\hline$\gamma_{2}$ & 21.57 & 21.74 \\
\hline
\end{tabular}

Table 8 - Values for parameters $\gamma_{1}$ and $\gamma_{2}$

\subsection{Comparison with test results}

4 The modified foundation model proposed in the previous section was validated against the results

5 of the laboratory tests described in Section 2. Figure 19 presents the comparisons between the force-

6 displacement envelopes predicted by the modified foundation model and the experimental results

7 when a $12 \mathrm{~mm}$ dowel is employed, while Figure 20 depicts the same comparisons for the case of 16 $\mathrm{mm}$ dowels. The experimental envelope was obtained by plotting the observed maximum and minimum forces along the full embedment range while the numerical results were obtained from the modified foundation model described above assuming $P$ ratios in the range of 1.5 to 3 . Figures 19 and 20 demonstrate that the estimations of the modified foundation model are in close agreement with the experimental results. The model is able to reproduce key response parameters such as stiffness and embedment strength well within the bounds of the experimentally observed values in all cases. In particular, the experimental force-displacement relationships of parallel to grain specimens (Figures 19a and 20a) is well simulated up to displacements of $4 \mathrm{~mm}$ (i.e. strain levels of around $8 \%$ ). However, in the case of perpendicular to grain response, the foundation model produces noticeable differences in the post-elastic range with appreciable strain hardening in the numerical estimations in lieu of the almost perfectly-plastic response observed in the experiments. This is attributed to the inability of the continuum FE model to reproduce localized splitting between fibres at large deformations and the associated softening effects. Nevertheless, the foundation model provides estimates within the experimentally observed bounds for embedment displacements of up to $2.5 \mathrm{~mm}$ in both cases (Figures $19 \mathrm{~b}$ and 20b). An important feature of the 
1 numerical responses presented in Figure 19 and 20 is their relatively low dependence on the radius

2 of the foundation volume adopted (characterized here by the parameter P as introduced in Equation

3 8). This provides confidence in the effectiveness of Equations 9 to 12 in liberating the numerical 4 response from a unique value of the foundation zone radius making the model consistently 5 applicable to a wider range of varying geometrical configurations.

6

7

8

9

10

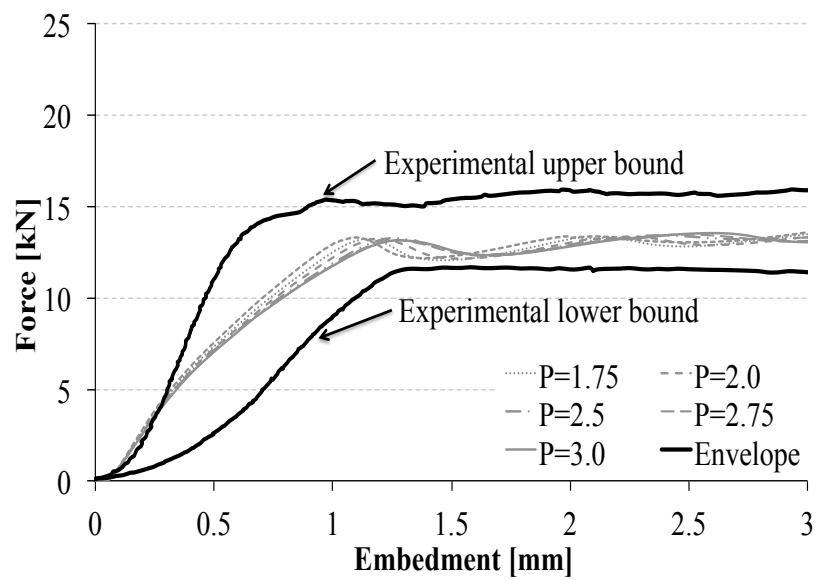

a) Parallel to grain

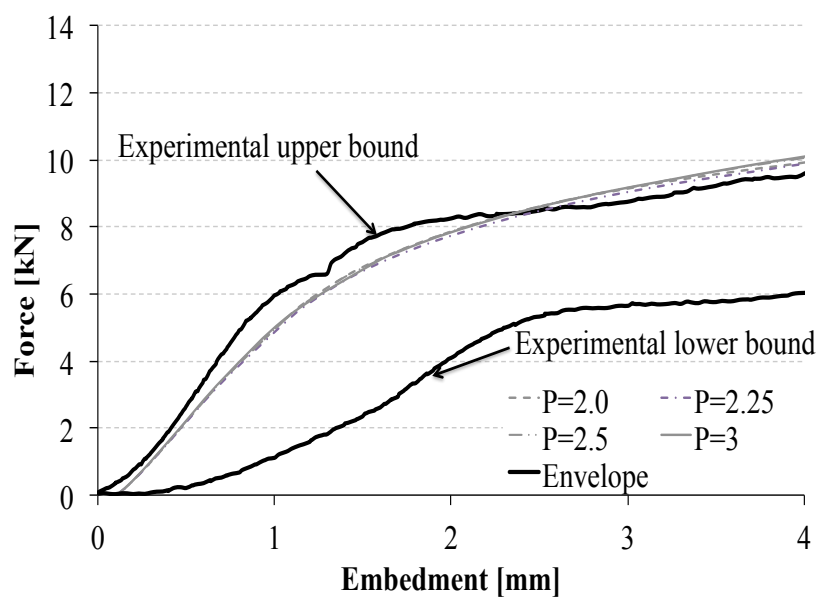

b) Perpendicular to grain

Figure 19. Comparison of experimental and numerical force-embedment envelope relationships $(\mathrm{d}=12 \mathrm{~mm})$.

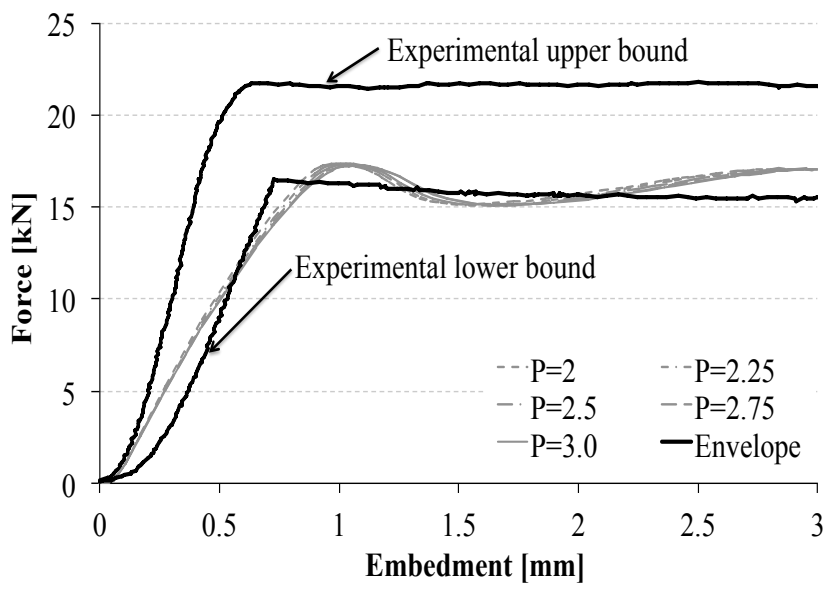

a) Parallel to grain

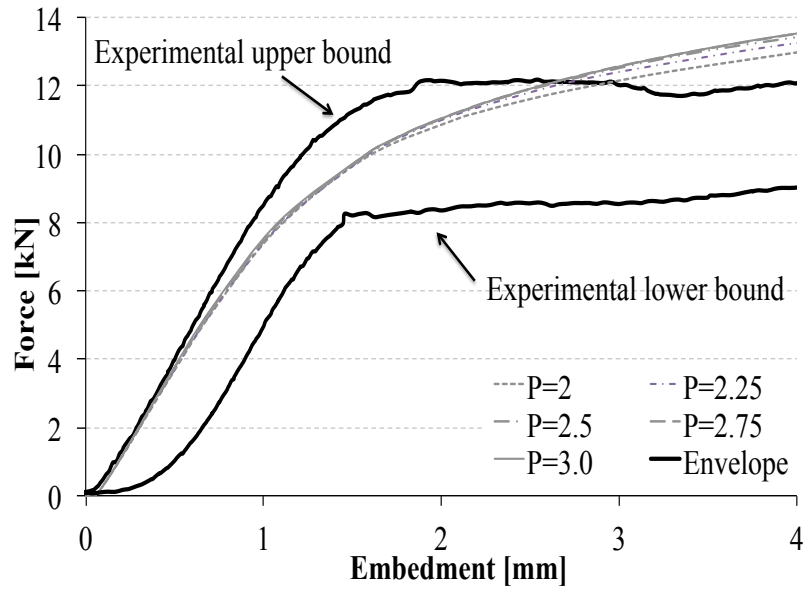

b) Perpendicular to grain

Figure 20. Comparison of experimental and numerical force-embedment envelope relationships $(\mathrm{d}=16 \mathrm{~mm})$. 
1 Finally, Figures 21 and 22 compare the experimentally observed displacement contours obtained by means of the DIC against the numerical predictions of the modified foundation model at yield for two representative parallel-to-grain and perpendicular-to-grain specimens, respectively. It is evident from these figures that the proposed foundation model is able to replicate the general tendencies in magnitude and distribution of the deformations within the specimens. A concentration of relatively higher localized strains immediately below the dowel are predicted by the FE model which can be attributed to the numerical definition of hard contact between timber and steel and the averaged nature of the material properties employed for the foundation model. Nevertheless, a good correlation of mean displacement orientations is apparent from Figures 21 and 22 including the effects of grain direction on the predominant contour alignment as discussed above.

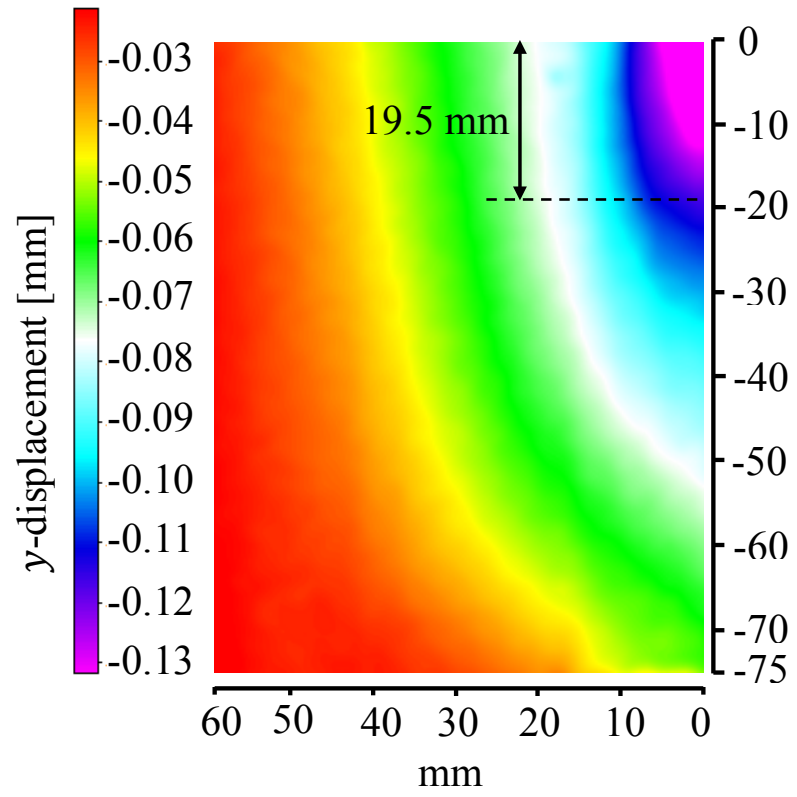

a) Experiment

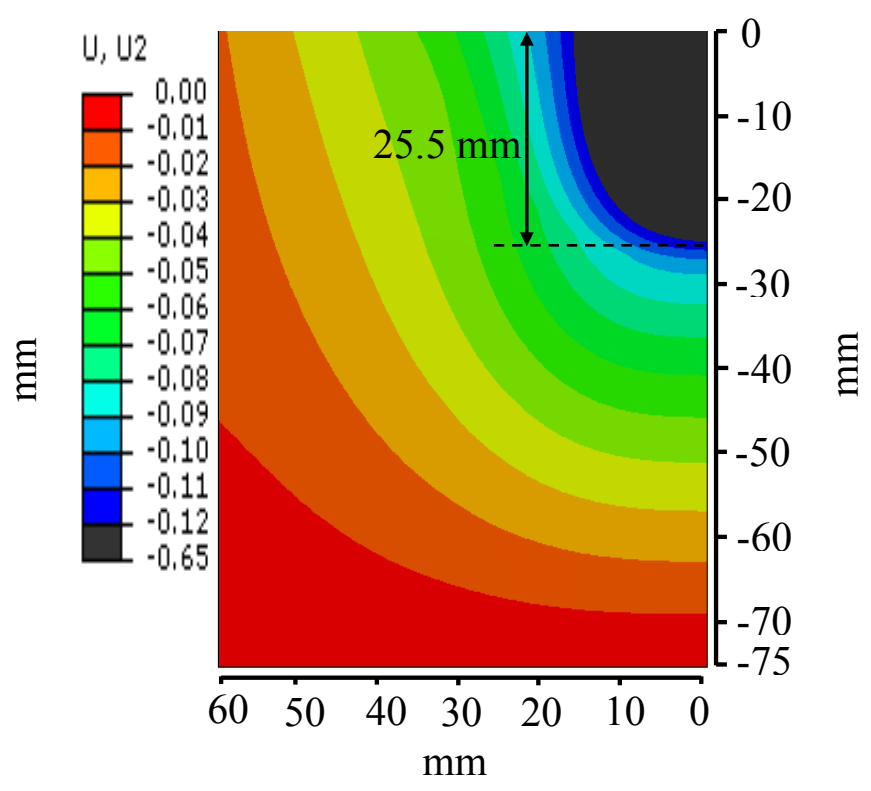

b) Modified foundation FE model

Figure 21. Comparison of experimental and numerical displacement contours at yield. Embedment parallel to grain $(\mathrm{d}=12 \mathrm{~mm})$ 


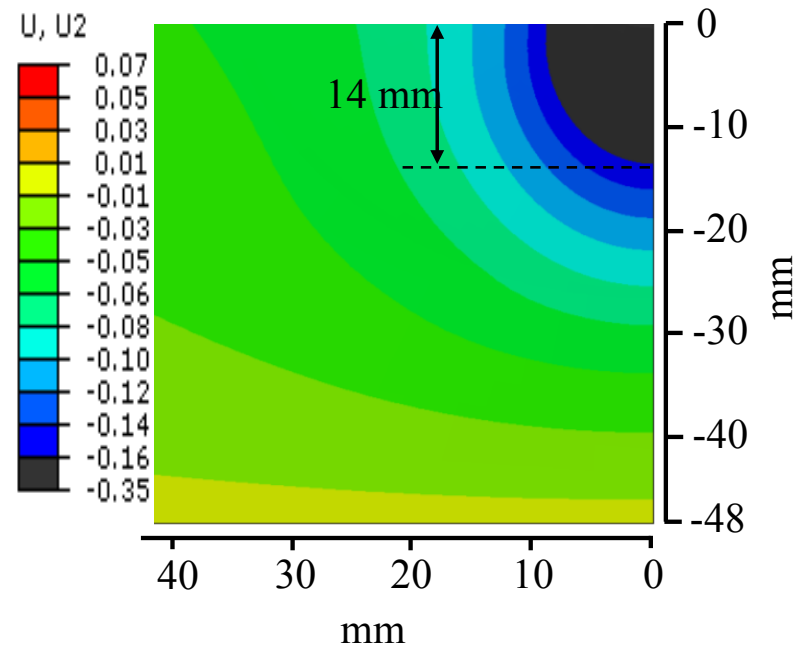

b) Modified foundation FE model

a) Experiment

Figure 22. Comparison of experimental and numerical displacement contours at yield. Embedment perpendicular to grain $(\mathrm{d}=12 \mathrm{~mm})$

\section{Conclusions}

This paper has studied the embedment behaviour of single-dowel connections in Scandinavian Spruce with loads acting parallel and perpendicular to the grain direction. An experimental programme comprising 39 connection details with $12 \mathrm{~mm}$ and $16 \mathrm{~mm}$ dowels was described. The tests enabled detailed monitoring of the evolution of local strain concentrations around the fastener at increasing levels of bearing deformation by means of Digital Image Correlation (DIC) techniques. This served to examine the tendency of the strain contours to align with the direction of the grain. Also, the differences in load bearing mechanisms brought about by the different grain orientations were found to influence the degree to which strain concentrations are able to penetrate in the wood material beneath the dowel area. To this end, significant increments in the highly strained area for parallel-to-grain specimens were observed in comparison with perpendicular-tograin joints where a tendency towards an increasingly more localized concentration of the area of highest strains was documented. 
1 A foundation model initially developed for Douglas-fir (Pseudotsuga menziesii) timber was improved and adopted in this study to model the embedment response of Scandinavian Spruce Glulam (Picea abies). The proposed model is based on the definition of equivalent material parameters for the crushing region around the dowel hole. In order to improve the versatility of the FE simulations, new relationships for the estimation of material characteristics as a function of the crushing volume were suggested. The validity and accuracy of the proposed modified foundation models were examined against the experimental results, and good agreement was found between the experimental response and the numerical simulations, although this needs to be examined further in future studies covering alternative joint configurations and loading conditions (such as the influence of group effects and other edge conditions). Overall, the results presented in this paper suggest that the proposed modelling procedures can be employed in the assessment and design of single-dowel joints or as the basis for the formulation of alternative simplified approaches.

\section{References}

1. M. Patton-Mallory, S.M. Cramer, F.W. Smith and P.J. Pellicane, Nonlinear Material Models for Analysis of Bolted Wood Connections, Journal of Structural Engineering, Vol. 123, pp. 1063-1070, 1997.

2. M. Patton-Mallory, P.J. Pellicane, and F.W. Smith, Qualitative assessment of failure in bolted connections: maximum stress criterion, Journal of Test Evaluations, Vol. 26, pp. 489496, 1998.

3. ABAQUS, ABAQUS theory manual, version 5.4. Hibbit, Karlsson and Sorensen Inc., 1994.

4. D.M. Moses and H.G.L. Prion, Stress and failure analysis of wood composites: a new model, Composites: Part B, Vol. 35, pp. 251-261, 2004.

5. N. Kharouf, G. McClure and I. Smith, Elasto-plastic modelling of wood bolted connections, Computers and Structures, Vol. 81, pp. 747-754, 2003.

6. R.O. Foschi, Load-slip characteristics of nails, Wood Science, Vol.7, pp. 69-76, 1974. 
7. J.P. Hong, Three-dimensional nonlinear finite element model for singe and multiple doweltype wood connections, PhD thesis, Program of Forestry, University of British Columbia, Canada, 2007.

8. European Standard CEN EN 408:2010+A1. Timber Structures- Structural timber and glued laminated timber - determination of some physical and mechanical properties, July 2012.

9. European Standard CEN EN 383:2007. Timber Structures- Test methods - Determination of embedment strength and foundation values for dowel type fasteners. January 2007.

10. EN 1995-1-1:2004+A2:2014, Eurocode 5: Design of timber structures - Part 1-1: Common rules and rules for buildings. Brussels, CEN, European Committee for Standardization, 2014.

11. LaVision UK Ltd. www.lavisionuk.com. [Last accessed 15/05/2015].

12. F. Chen, X. Chen, X. Xie, X. Feng, L., Yang, Full-field 3D measurement using multicamera digital image correlation system, Optics and Lasers in Engineering, Vol. 51, pp. 1044-1052, 2013.

13. Davis. Product manual for Davis, version 8.2. LaVision GmbH. July 2014.

14. I. Smith, Coefficient of friction values applicable to contact surfaces between mild steel connectors such as bolts and dry European white wood, Journal of the Institute of Wood Science, Vol. 9, pp. 229-234, 1983.

15. ABAQUS. ABAQUS theory manual, version 6.14, Hibbit, Karlsson and Sorensen Inc., 2014.

16. European Standard CEN EN 338:2009. Structural Structures - Strength Classes. October 2009. 